\title{
Práctica anticonceptiva y clases sociales en México: la experiencia reciente
}

\author{
Mario Bronfman, Elsa López \\ y Rodolfo Tuirán*
}

El uso de anticonceptivos ha ido extendiéndose en México en los últimos años. Este proceso ha sido registrado por las diferentes encuestas de alcance nacional, las que además dan cuenta de cambios en los patrones de uso, en las instituciones proveedoras, en la estructura de edades de las usuarias, etc. La Encuesta Nacional Demográfica (END) permite evidenciar las pautas más recientes en las que el fenómeno más relevante es el incremento de la esterilización femenina. Este trabajo se apoya en la END y muestra además algunas características de la distribución de este método en los diferentes grupos sociales, las instituciones que lo practican y la especialización de la "clientela", la oportunidad de la realización y la magnitud del incremento.

\section{Introducción}

Este trabajo intenta aportar información que complemente la ya existente en el análisis de los patrones anticonceptivos de la población mexicana. En él pretendemos actualizar la evolución del uso de métodos anticonceptivos en México. Además, incursionamos de manera exploratoria en la relación entre esos patrones y la pertenencia de clase. La hipótesis más general que subyace a esta relación postula la existencia de comportamientos diferenciales en cuanto a la anticoncepción. Dejamos para trabajos futuros - y aquí se encuentra una de las principales limitaciones de este trabajo- la formulación y puesta a prueba de algunas hipótesis que trasciendan la mera descripción de las diferencias.

Los datos que se presentan en este trabajo provienen principalmente de la Encuesta Nacional Demográfica (END), proyecto interinstitucional encabezado por el Consejo Nacional de Población, cuyo trabajo de campo se realizó entre febrero y abril de 1982.

Este trabajo consta de cinco apartados y un apéndice metodológico. En el primero, se describe muy brevemente la evolución reciente del uso de anticonceptivos en México. Del segundo al cuarto apartado se caracteriza a las usuarias de métodos anticonceptivos de acuerdo a un conjunto

* Profesores-investigadores del Centro de Estudios Demográficos y de Desarrollo Urba no de El Colegio de México. Los autores desean agradecer la valiosa colaboración de la actuaria Martha Elva Gómez, de la Unidad de Cómputo de El Colegio de México. así como la de Alejandro Cervantes y Francisco Hernández en la realización de este trabajo. 
de variables, tales como la pertenencia de clase, ${ }^{1}$ el tipo de método utilizado y el lugar de obtención. Finalmente, en el quinto apartado se realiza un análisis pormenorizado de las mujeres esterilizadas, pues la esterilización es el método que ha observado los incrementos más notables en los últimos años.

\section{Evolución reciente del uso de anticonceptivos en México}

Resulta innecesario citar la larga lista de documentos oficiales y trabajos académicos que señalan que México ha presenciado un importante descenso en su tasa de crecimiento demográfico, atribuible, fundamentalmente, a la disminución de la fecundidad. Las razones por las cuales se ha producido este fenómeno concitan menos unanimidad que su señalamiento. Sin embargo, parece haber un acuerdo generalizado en atribuir a la expansión de la cobertura de anticonceptivos una responsabilidad importante en el abatimiento de las altas tasas de fecundidad.

Afortunadamente, se han estado recopilando datos con cierta regularidad en encuestas con muestras nacionales, lo que permite comprobar la evolución del uso de anticonceptivos y verificar su incremento. En el cuadro 1 se puede observar que entre 1976 y 1982 se produjo un aumento en la proporción de mujeres en edad fértil unidas que usan anticonceptivos, que pasó de 30.2 a 47.7 por ciento. Esto significa un aumento relativo de $57.9 \%$ en el total de ese grupo de mujeres. A su vez, este incremento se produjo en todos los grupos de edad con altibajos de menor importancia. Ello se refleja en la composición por edades de las usuarias, que mantienen casi la misma estructura entre 1976 y 1982 (ver cuadro 2) y en las diferencias porcentuales relativas que se presentan en el cuadro 1. Según éste, entre la Encuesta Mexicana de Fecundidad (EMF) y la END, es decir, entre 1976 y 1982, ningún grupo etáreo tuvo incrementos relativos de usuarias inferiores a 46 por ciento.

El aumento en la proporción de usuarias se ha concentrado en los niveles educativos inferiores. Así, entre 1978 y 1982, las usuarias en el grupo de más baja escolaridad pasan de 17 a 27 por ciento y en el de las que tienen escolaridad primaria de 29 a 33 por ciento. En los grupos de más alta escolaridad o no se registran cambios o incluso hay un descenso en la proporción de usuarias (cuadro 3).

No se observan modificaciones importantes en cuanto al estado conyugal de usuarias y no usuarias. Las primeras se siguen reclutando, casi exclusivamente, entre las mujeres unidas, mientras que las no usuarias se dividen casi en partes iguales entre unidas y no unidas (cuadro 4).

${ }^{1}$ La composición de las clases sociales que se usa en este trabajo fue tomada de Bronfman y Tuirán (1984). 
CUADRO 1

Porcentaje de mujeres unidas que usan métodos anticonceptivos por grupos de edad e incrementos porcentuales - bruto y relativoregistrados en la EMF (1976), la ENPUA (1978) y la END (1982)

\begin{tabular}{|c|c|c|c|c|c|c|c|c|c|}
\hline \multirow[b]{2}{*}{ Edad } & \multirow{2}{*}{$\begin{array}{l}\text { EMF } \\
\text { (1) }\end{array}$} & \multirow{2}{*}{$\begin{array}{c}\text { ENPUA } \\
\text { (2) }\end{array}$} & \multirow{2}{*}{$\begin{array}{c}\text { END } \\
(3) \\
\end{array}$} & \multicolumn{3}{|c|}{ Distribución \% absoluta } & \multicolumn{3}{|c|}{ Distribución \% relativa } \\
\hline & & & & $(2-1)$ & $(3-1)$ & $(3-2)$ & $(2-1)$ & $(3-1)$ & $(3-2)$ \\
\hline $15-19$ & 14.2 & 23.0 & 20.7 & 8 & 6 & 23 & 2.0 & 45.8 & 10 \\
\hline $20-24$ & 26.7 & 4 & 45 & 15 & $1 \mathrm{~S}$ & & & 71.2 & \\
\hline $25-29$ & 38.6 & 4 & 56.6 & 7.1 & 18 & 10.9 & 8.4 & 6 & 23 \\
\hline $30-34$ & 38.0 & 5 & 59.8 & 15.2 & 21.8 & & 0 & & 12 \\
\hline 35 & 37.9 & 4 & 57.6 & & 19.7 & 14.4 & 1 & 52.0 & 33. \\
\hline $40-44$ & 25.1 & 33 & 42.8 & 8 & 17 & 9.1 & 34 & 7 & 52 \\
\hline $45-$ & 11.8 & 14. & 22.1 & 2 . & 10 & 7. & 22 & 87.3 & 52.4 \\
\hline Total & 30.2 & 40.0 & 47.7 & 9.8 & 17.5 & 7.7 & 32.5 & 57.9 & 16. \\
\hline
\end{tabular}

Fuente: Encuesta Mexicana de Fecundidad (1978); Encuesta Nacional de Prevalencia en el Uso de Métodos Anticonceptivos (1980) y Encuesta Nacional Demográfica (1982).

CUADRO 2

Distribución porcentual de las usuarias de métodos anticonceptivos por edad en EMF (1976), ENPUA (1978) y END (1982)

\begin{tabular}{lrrrrrr}
\hline & EMF & ENPUA & END & \multicolumn{3}{c}{ Distribución porcentual absoluta } \\
\cline { 6 - 7 } Edad & \multicolumn{1}{c}{$(1)$} & \multicolumn{1}{c}{$(2)$} & $(3)$ & $(2-1)$ & $(3-2)$ & $(3-1)$ \\
\hline $\mathbf{1 5 - 1 9}$ & 3.6 & 4.8 & 3.0 & 1.2 & -1.8 & -0.6 \\
$20-24$ & 16.2 & 21.9 & 17.7 & 5.7 & -4.2 & 1.5 \\
$25-29$ & 25.6 & 22.9 & 23.8 & -2.7 & 0.9 & -1.8 \\
$30-34$ & 21.6 & 21.2 & 21.4 & -0.4 & 0.2 & -0.2 \\
$35-39$ & 19.6 & 16.3 & 18.7 & -3.3 & 2.4 & -0.9 \\
$\mathbf{4 0 - 4 4}$ & 9.8 & 9.6 & 11.1 & -0.2 & 1.5 & 1.3 \\
$\mathbf{4 5 - 4 9}$ & 3.6 & 3.3 & 4.3 & -0.3 & 1.0 & 0.7 \\
Total & 100.0 & 100.0 & 100.0 & & & \\
\hline
\end{tabular}

Fuente: Encuesta Mexicana de Fecundidad (1978); Encuesta Nacional de Prevalencia en el Uso de Métodos Anticonceptivos (1980) y Encuesta Nacional Demográfica (1982).

CUADRO 3

Población femenina por condición de uso según nivel de escolaridad. ENPUA (1978) y END (1982)

\begin{tabular}{|c|c|c|c|c|c|c|c|c|}
\hline & \multicolumn{2}{|c|}{ Sin escolaridad } & \multicolumn{2}{|c|}{ Primaria } & \multicolumn{2}{|c|}{ Secundaria } & \multicolumn{2}{|c|}{ Prep. y univ. } \\
\hline & ENPUA & END & ENPUA & END & ENPUA & END & ENPUA & END \\
\hline Usuarias & 17.3 & 27.0 & 29.5 & 33.4 & 21.1 & 22.6 & 25.4 & 22.7 \\
\hline Ex usuarias & 8.3 & 9.7 & 12.7 & 9.7 & 13.0 & 6.1 & 12.3 & 4.4 \\
\hline No usuarias & 74.4 & 63.3 & 57.9 & 56.9 & 65.8 & 71.3 & 62.3 & 72.9 \\
\hline Total & 100.0 & 100.0 & 100.0 & 100.0 & 100.0 & 100.0 & 100.0 & 100.0 \\
\hline
\end{tabular}

Fuente: Encuesta Nacional de Prevalencia en el Uso de Métodos Anticonceptivos (1980) y Encuesta Nacional Demográfica (1982). 
CUADRO 4

Población femenina por estado conyugal según condición de uso. ENPUA (1978) y END (1982)

\begin{tabular}{lccccc}
\hline & \multicolumn{2}{c}{ Usuarias } & & \multicolumn{2}{c}{ No usuarias } \\
\cline { 2 - 3 } \cline { 5 - 6 } & ENPUA & END & & ENPUA & END \\
\hline Unidas & 96.3 & 95.4 & & 51.4 & 44.8 \\
Casada & 87.4 & 84.8 & & 44.0 & \\
Unión libre & 8.9 & 10.6 & & 7.4 & \\
No unidas & 3.7 & 4.4 & & 48.6 & 55.2 \\
Viuda & 0.3 & 0.6 & & 2.6 & \\
Divorciada/separada & 2.2 & 2.5 & & 4.8 & \\
Soltera & 1.2 & 1.3 & & 41.2 & \\
N.R. & - & 0.2 & & - & - \\
& 100.0 & 100.0 & & 100.0 & 100.0 \\
\hline
\end{tabular}

Fuente: Encuesta Nacional de Prevalencia en el Uso de Métodos Anticonceptivos (1980) y Encuesta Nacional Demográfica (1982).

Si bien las coberturas siguen siendo más altas en las áreas urbanas y metropolitanas que en las rurales ( 55.3 y 59.7 por ciento contra $38.5 \%$ ), los incrementos relativos entre 1976 y 1982 han sido más importantes en las áreas rurales, donde sobrepasan el $140 \%$, que en las urbanas, donde no llegan a $30 \%$. Hay que hacer notar, sin embargo, que estas cifras están fuertemente influidas por los niveles de la cobertura en 1976. Para atenuar este efecto hemos calculado el incremento real (END-EMF) sobre el incremento posible (100-EMF). También para este indicador el aumento en las áreas rurales es mayor que en las urbanas (26.9\% contra $22.5 \%)$, confirmando la tendencia que antes apuntábamos (cuadro 5).

CUADRO 5

Distribución porcentual de usuarias actuales entre las mujeres unidas por tamaño de la localidad de residencia. EMF (1976), ENPUA (1978), END (1982)

\begin{tabular}{lccc}
\hline & EMF $^{1}$ & ENPUA $^{2}$ & END $^{3}$ \\
\hline Rural & 15.9 & 25.1 & 38.5 \\
Urbana & & 51.9 & 55.3 \\
Urbana (incluye A.M.) & 45.7 & 55.1 & 57.9 \\
A.M. & - & 56.9 & 59.7 \\
Total & 30.2 & 41.5 & 47.7 \\
\hline
\end{tabular}

Fuente: Encuesta Mexicana de Fecundidad (1978); Encuesta Nacional de Prevalencia en el Uso de Métodos Anticonceptivos (1980) y Encuesta Nacional Demográfica (1982).

1 La EMF hace el corte entre rural y urbano en 20000 habitantes e incluye en el grupo de más de 20000 habitantes a las tres áreas metropolitanas (A.M.).

${ }^{2}$ La ENPUA hace el corte entre rural y urbano en 15000 habitantes.

${ }^{3} \mathrm{La}$ END hace el corte entre rural y urbano en 20000 habitantes. 
En cuanto al método utilizado, ha habido algunos cambios entre 1978 (Encuesta Nacional de Prevalencia en el Uso de Métidos Anticonceptivos, ENPUA) y 1982 (END), que vale la pena señalar. Los métodos efectivos pasan de 76.6 a 82.9 por ciento, pero este aumento se compone de descensos en el peso de las "pastillas" ( $35.4 \%$ contra $29.2 \%$ ) y del DIU ( $16.1 \%$ contra $13.8 \%$ ), y aumentos en la "operación femenina" (17.8\% contra $28.1 \%$ ) y las inyecciones ( $7.0 \%$ contra $10.6 \%$ ). En el caso de la esterilización, se trata de un incremento relativo de $58 \%$ en sólo tres años; éste es el cambio más importante observado, sobre todo por su irreversibilidad y, en consecuencia, por su impacto en la fecundidad (cuadro 6). La ex-

CUADRO 6

Distribución porcentual de las usuarias actuales según método que utilizan. ENPUA (1978) y END (1982)

\begin{tabular}{lrrcc}
\hline Método & ENPUA & END & $\begin{array}{c}\text { Distribución } \\
\% \text { absoluta }\end{array}$ & $\begin{array}{c}\text { Distribución } \\
\text { \% relativa }\end{array}$ \\
\hline Operación femenina & 17.8 & 28.1 & 10.3 & 57.9 \\
Pastillas & 35.4 & 29.7 & -5.7 & -16.1 \\
Inyecciones & 7.0 & 10.6 & -3.6 & -14.3 \\
DIU & 16.1 & 13.8 & -2.3 & -14.3 \\
Otros no tradicionales & 6.7 & 4.6 & -2.1 & -31.3 \\
Otros tradicionales & 17.0 & 13.2 & -3.8 & -22.4 \\
Total & 100.0 & 100.0 & & \\
\hline
\end{tabular}

Fuente: Encuesta Nacional de Prevalencia en el Uso de Métodos Anticonceptivos (1980) y Encuesta Nacional Demográfica (1982).

pansión de la esterilización ha sido especialmente notable en la zona rural, donde la proporción de usuarias que declararon estarlo se duplicó entre 1978 y 1982 (cuadro 7). Sería importante tratar de identificar las acciones, específicas o no, que han producido estos cambios, así como la modalidad con que ellas se realizan. En esta línea, nuestra información permite sólo señalar la expansión de las acciones del Instituto Mexicano del Seguro Social (IMSS), especialmente en las áreas rurales, donde el porcentaje de usuarias que atiende casi se ha duplicado (15.9\% contra $30.1 \%$ ) (cuadro 8) y apuntan a la "preferencia" que esa institución ha ido adquiriendo por la esterilización femenina $(52.6 \%$ del total de intervenciones del IMSS) (véase el cuadro 9).

Hemos resumido este panorama para evidenciar el notable aumento del uso de anticonceptivos y para señalar algunos cambios y algunas constantes en las caracteríticas de las usuarias. 


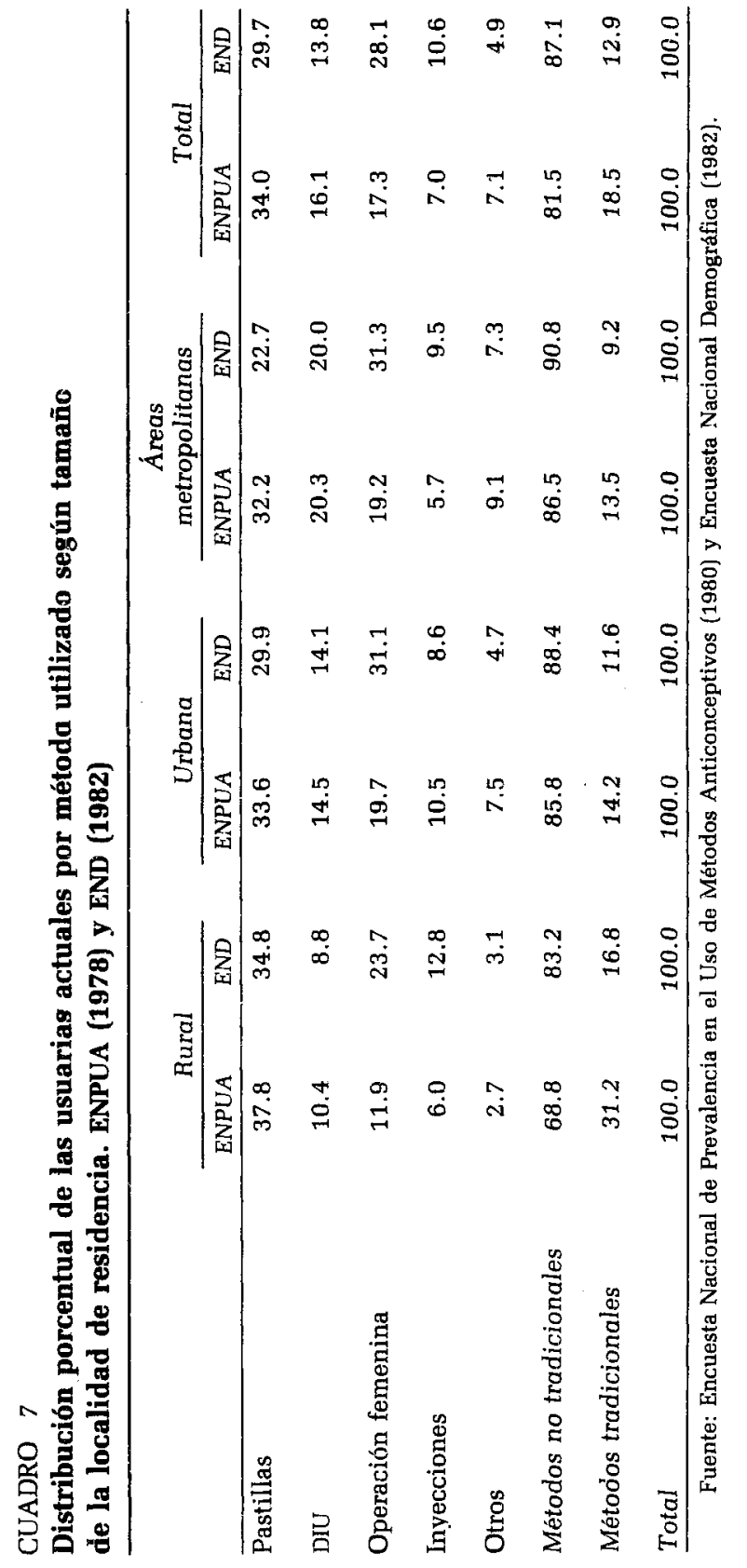




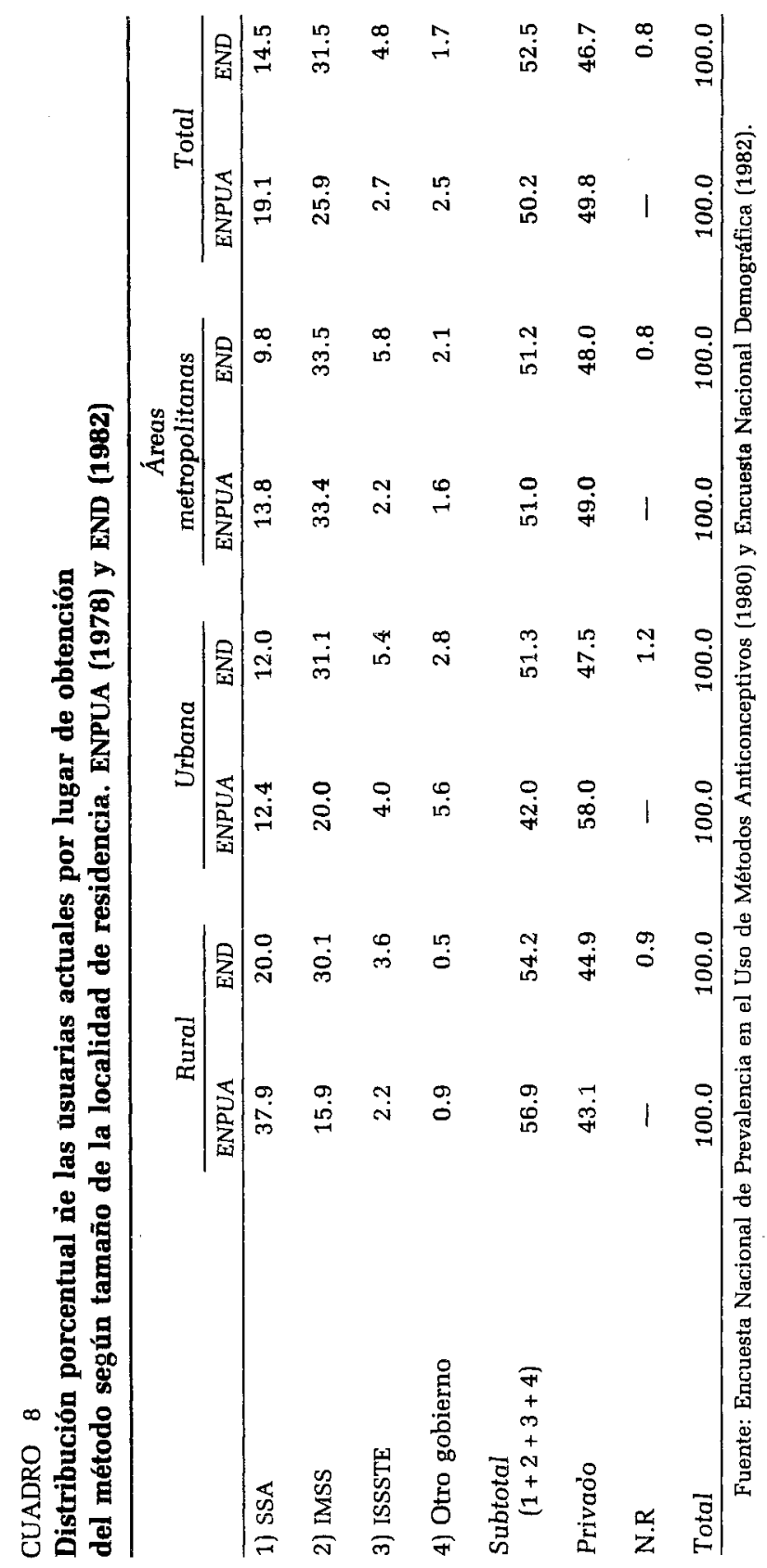




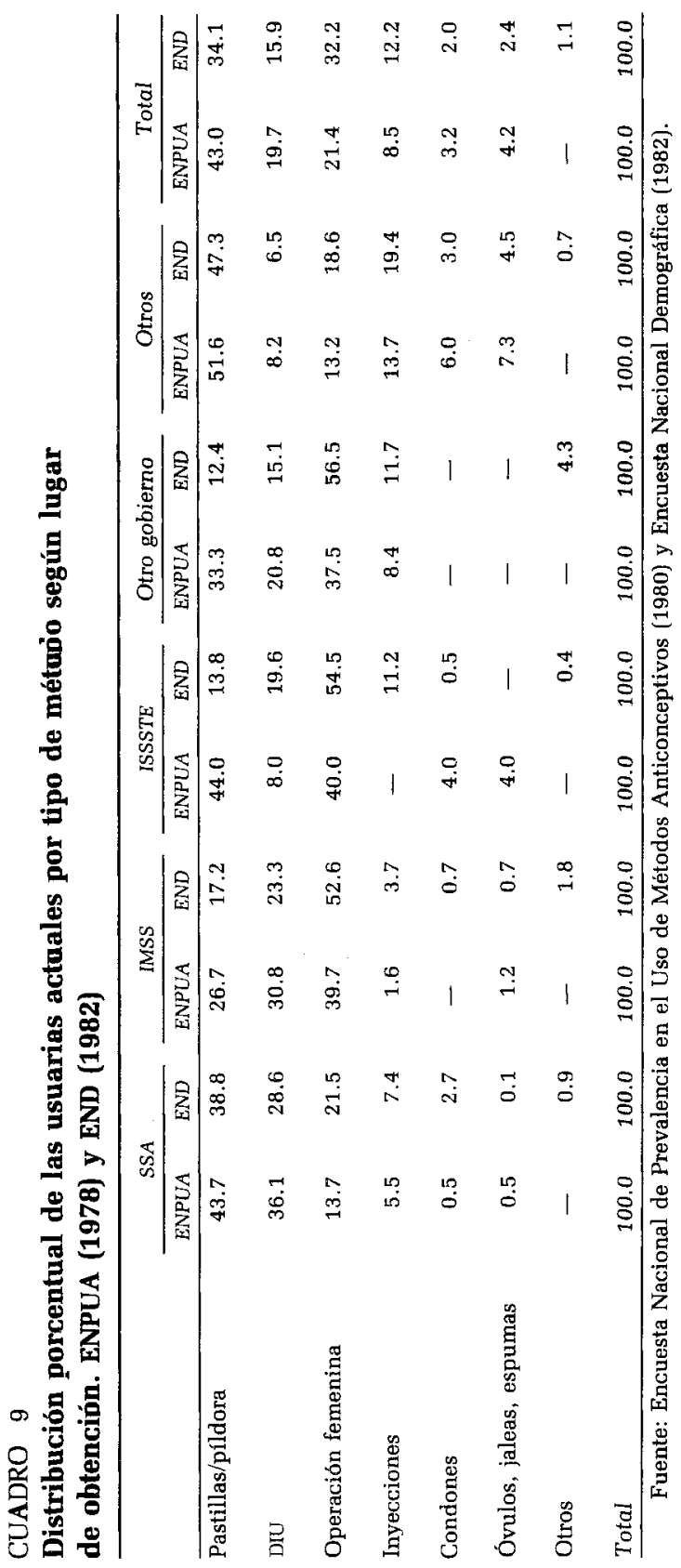




\section{Práctica anticonceptiva y clase social}

El comportamiento de los distintos grupos sociales en materia de práctica anticonceptiva puede ser examinada a partir de los datos contenidos en el cuadro 10. En él se presenta información acerca de la condición de uso de anticonceptivos entre las mujeres actualmente unidas por clase social de pertenencia.

A nivel nacional, los datos disponibles indican que $47.7 \%$ de las casadas o convivientes usaban al momento de realizarse la encuesta algún método anticonceptivo. Cabe hacer notar que la proporción más alta de uso correspondió a los grupos no agrícolas; en ellos, una de cada dos mujeres unidas ( $52.3 \%$ ) declaró practicar en ese momento la anticoncepción, mientras que en los grupos agrícolas sólo una de cada tres (34.2\%) hacía uso de esta opción cuando se levantaba la encuesta.

Los datos del cuadro 10 nos permiten profundizar en el estudio de la relación entre práctica anticonceptiva y ubicación social de las mujeres entrevistadas. A primera vista, puede apreciarse que entre las mujeres actualmente unidas, las diferencias en las proporciones de uso por clase social no parecen ser muy marcadas. A continuación detallamos algunos de los hallazgos más relevantes que se desprenden de la información contenida en el cuadro citado.

1) Entre los grupos no agrícolas, se advierte un comportamiento más o menos homogéneo. De hecho, en casi todos ellos la proporción de usuarias actuales respecto al total de mujeres unidas alcanzó un nivel muy cercano a $55 \%$. Los únicos grupos que se alejan significativamente de este patrón de comportamiento son la fuerza de trabajo "libre" no asalariada, y la fracción del proletariado típico que se ubica en pequeños establecimientos fabriles; en estos grupos, la proporción de uso se situó en alrededor de $45 \%$.

2) Entre los grupos agrícolas, las diferencias por clase son también mínimas. Con excepción del proletariado agrícola, en el resto de los grupos sociales se observa que las usuarias de métodos anticonceptivos representan alrededor de $30 \%$ de las mujeres unidas; en contraste, entre los asalariados agrícolas la proporción de uso casi alcanzó $40 \%$. Es importante destacar que el porcentaje de usuarias que registra esta clase no está muy alejado de los valores observados por los grupos no agrícolas que hemos denominado "fuerza de trabajo 'libre' no asalariada" y "proletariado típico en pequeños establecimientos".

3) Los anteriores ítems proporcionan los elementos necesarios para plantear a título hipotético la existencia de tres distintas pautas de comportamiento en materia de práctica anticonceptiva en México, cada una de las cuales estaría asociada a grupos sociales particulares.

a) El primer patrón de comportamiento está definido por los grupos en los que la práctica anticonceptiva se encuentra ya bastante difundida. 


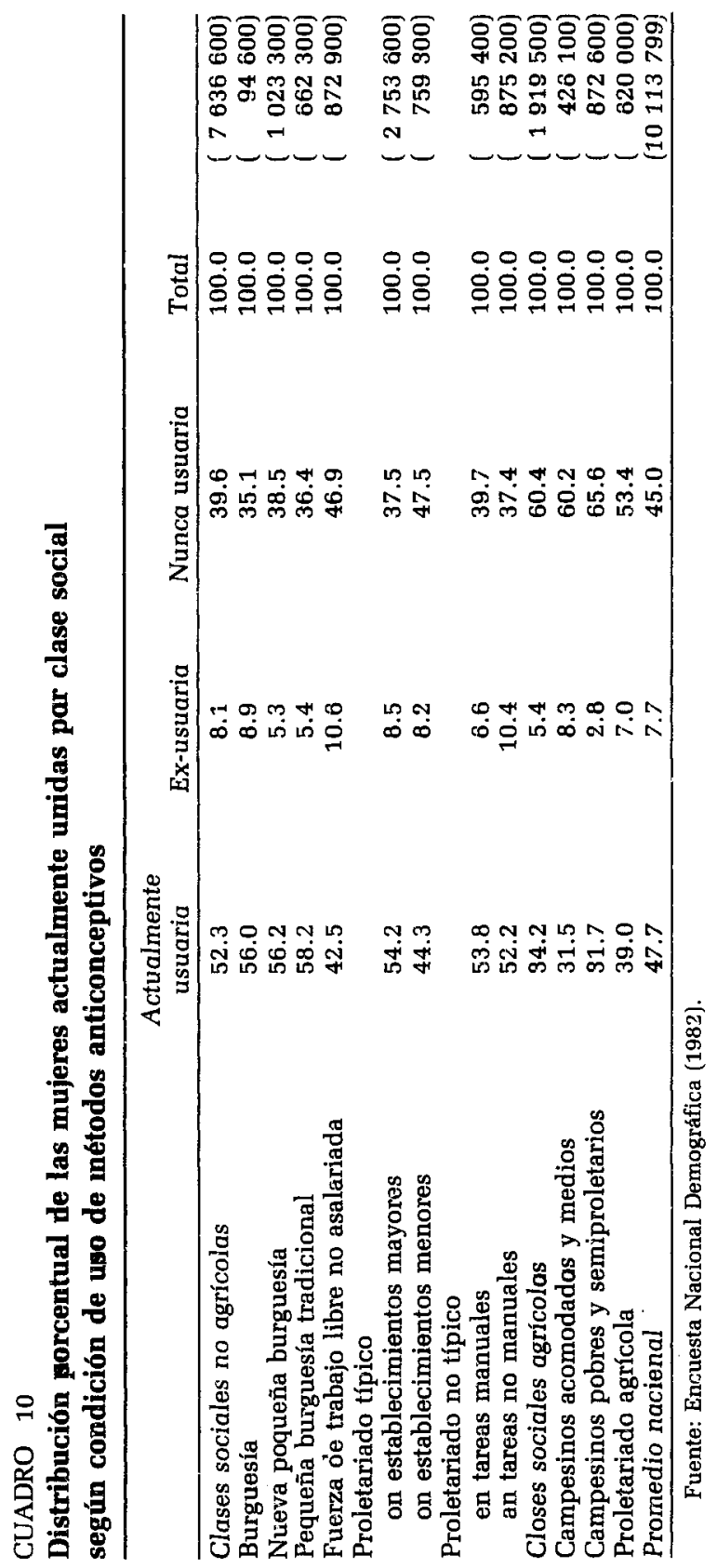


A este conjunto pertenecen la burguesía, la nueva pequeña burguesía, la pequeña burguesía tradicional, la fracción del proletariado típico que se ubica en establecimientos fabriles mayores y las dos fracciones del proletariado no típico. Si bien entre estos grupos existen diferencias en las proporciones de uso, éstas son moderadas. De hecho, la diferencia porcentual es de tan sólo seis puntos entre el grupo que muestra el nivel más alto de uso (pequeña burguesía tradicional, $58.2 \%$ ) y la clase que registra el nivel más bajo (proletariado no típico en tareas no manuales, $52.2 \%$ ). Es importante señalar que en este conjunto se incluyen, por una parte, los sectores sociales que adoptaron la anticoncepción en fechas muy recientes y, por otra, los grupos que desde tiempo atrás y de manera bastante generalizada han ejercido esta práctica, como es el caso de la burguesía y la nueva pequeña burguesía.

b) Una segunda pauta de comportamiento la configuran los grupos que muestran niveles de uso que se encuentran por debajo de la media nacional, pero que no se alejan demasiado de ésta. A este conjunto pertenecen la fuerza de trabajo "libre" no asalariada, el proletariado típico en pequeños establecimientos y el proletariado agrícola.

c) Por último, el tercer patrón de comportamiento corresponde a los grupos sociales que observan las menores proporciones de usuarias de métodos anticonceptivos entre las mujeres unidas. En este conjunto se incluyen sectores sociales tan disímiles como los campesinos acomodados y medios, y los campesinos pobres y semiproletaríos.

A la luz de los datos del cuadro 10 puede concluirse entonces que entre las mujeres unidas las diferencias por clase en las proporciones de uso no parecen ser, en la actualidad, muy marcadas. Si bien se observan variaciones importantes al pasar de los grupos no agrícolas a los agrícolas, no sucede lo mismo cuando se examinan las diferencias al interior de cada uno de estos agregados.

En el cuadro 11 se presenta información sobre el porcentaje de mujeres unidas que utilizan anticonceptivos por clase social según su edad. En él se podrá apreciar que a diferencia de las proporciones de uso agregadas, cuyo comportamiento por clase examinamos en los párrafos anteriores, existen pautas más diferenciadas cuando se controla la edad actual de las entrevistadas casadas o convivientes. En términos generales, puede advertirse que entre los 15 y los 24 años de edad se observan las mayores diferencias en el uso por clase social; éstas se acortan notablemente entre los 25 y los 34 años y se estrechan aún más a partir de los 35 años de edad.

La evidencia disponible revela que dentro del grupo etáreo 15-24 destacan por sus elevados niveles de uso las mismas clases sociales no agrícolas que configuran el patrón de comportamiento que definimos en el punto 3, ítem a). Sin embargo, si antes no se observaban mayores diferencias entre estos grupos, al aislar el efecto de la variable edad se puede 


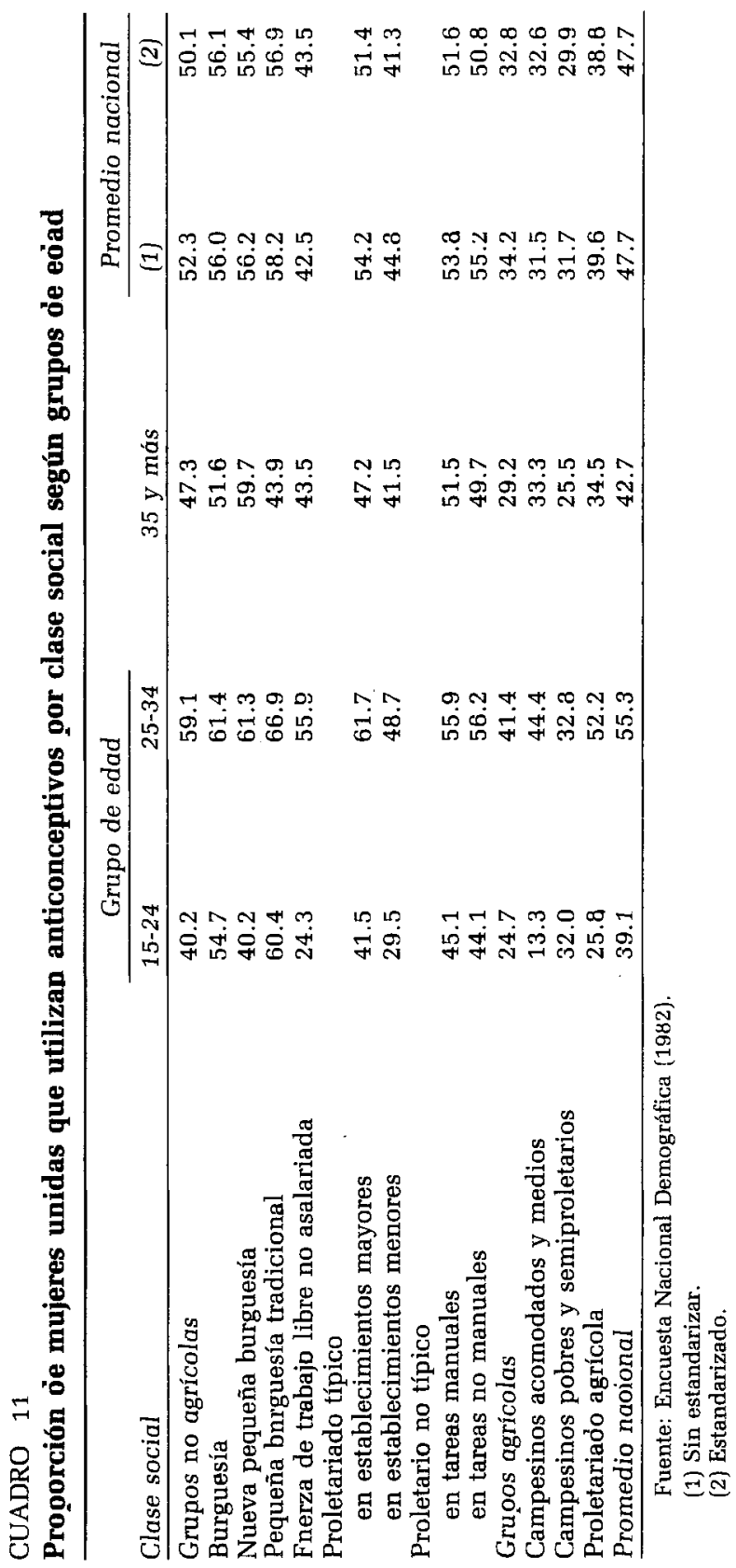


apreciar, en cambio, una clara tendencia a un menor uso de anticonceptivos a medida que se pasa de las clases que poseen el control sobre los medios de producción a los grupos c. - sólo disponen de su fuerza de trabajo. La información muestra que las proporciones de usuarias activas entre la burguesía y la pequeña burguesía tradicional ascienden al 55 y 60 por ciento, respectivamente, de las mujeres unidas en el grupo de edad 1524 , mientras que en la fracción del proletariado típico en establecimientos mayores y en las dos distintas fracciones del proletariado no típico los niveles de uso varían entre el 40 y el 45 por ciento.

Las menores proporciones de usuarias activas en el grupo etáreo 1524 se observan entre las clases que conforman los patrones de comportamiento que definimos en el punto 3, ítems b) y c). Cabe hacer notar la homogeneidad en el uso de anticonceptivos que muestran los grupos que hemos denominado "fuerza de trabajo 'libre' no asalariada", "proletariado típico en establecimientos menores" y "asalariados agrícolas". Asimismo, puede destacarse que entre las clases agrícolas se observa un fenómeno peculiar: son las mujeres de los grupos que ocupan posiciones más desfavorecidas en la estructura social las que presentan las mayores proporciones de uso.

Entre los 25 y 34 años de edad se registra la mayor proporción de usuarias activas en todas las clases sociales. En el cuadro 11 se puede apreciar que a nivel nacional 55 de cada 100 mujeres unidas que se sitúan en ese grupo etáreo practican la anticoncepción. Esta relación no varía significativamente entre los grupos no agrícolas. Así, mientras que la burguesía, las dos fracciones de la pequeña burguesía y el proletariado típico en establecimientos mayores muestran niveles de uso superiores a $60 \%$, en el resto de las clases no agrícolas las proporciones varían entre 49 y 56 por ciento. Se advertirá que las diferencias por clase son notablemente menores en el grupo 25-34 años que las observadas en las edades más jóvenes. A su vez, entre los grupos agrícolas llama la atención el índice relativamente alto de usuarias activas que ostenta el proletariado, alcanzando incluso niveles semejantes a los que muestran algunas de las clases no agrícolas $(51.2 \%)$.

Por último, entre las mujeres de 35 años y más se puede advertir que los niveles de uso son, en todas las clases sociales, bastante menores que los registrados en el grupo etáreo anterior. Se observará también que existen diferencias por clase en el uso de anticonceptivos, aunque bastante más moderados que en las edades más jóvenes.

En conclusión, los resultados anteriores ofrecen cierta base para sostener que entre los distintos grupos sociales existen diferencias en el nivel de uso de anticonceptivos, siendo particularmente marcadas en las edades más jóvenes. 
3. Tipo de método y clase social

Es de particular interés examinar el comportamiento que muestran las distintas clases sociales en sus preferencias por los diversos métodos anticonceptivos. La bibliografía al respecto no es muy abundante, por lo que creemos oportuno dedicar un capítulo al análisis de esta relación.

Las principales conclusiones que se pueden extraer de nuestros datos son:

1) Los métodos más usados entre las distintas clases sociales son la pildora anticonceptiva y la operación femenina, aunque, en general, se observa una mayor utilización del primero.

2) El segundo orden de prevalencia corresponde al DIU y la inyección. En casi todos los grupos sociales se observa que el DIU es el método más usado después de la pildora y la esterilización.

3) El tercer orden de prevalencia lo ocupan los llamados métodos tradicionales. En algunos grupos sociales es particularmente elevada la proporción de usuarias que recurren a métodos tales como el ritmo, el retiro $\mathrm{y}$ otros.

Como el tipo de método usado varía marcadamente con la edad, en la construcción de los cuadros 13, 14, 15 y 16 hemos tomado en cuenta esa variable. A nivel nacional, la evidencia disponible permite señalar que en las edades jóvenes predomina el uso de la pastilla, siguiendo en orden de preferencia el DIU y luego la inyección; sin embargo, al aumentar la edad se reduce significativamente el uso de estos métodos, en especial el de la pildora, creciendo la importancia de la operación femenina. La esterilización constituye el método más usado a partir de los treinta años de edad.

Si ahora el análisis se centra en el tipo de método que predomina con la edad según clase social, es posible obtener algunas interesantes conclusiones:

1) El examen de los datos correspondientes a las mujeres que integran el grupo 20-24 años de edad revela que en casi todas las clases sociales el método más utilizado es la pildora, alcanzando proporciones que superan $30 \%$ de las mujeres unidas actualmente usuarias de este grupo etáreo según la clase social de pertenencia.

2) Entre las usuarias de 20 a 24 años se observa que después de la pastilla se prefiere el DIU o la inyección. Llama la atención que este último método alcance proporciones relativamente altas de usuarias entre las mujeres que integran los grupos que hemos denominado "proletariado típico en establecimientos mayores" y "proletariado no típico en tareas no manuales", así como entre los campesinos pobres y semiproletarios. En el resto de los grupos se observa una marcada preferencia de las mujeres jóvenes por el DIU, siendo éste el método más utilizado después de la pildora. 
PRÁCTICA ANTICONCEPTIVA Y CLASES SOCIALES

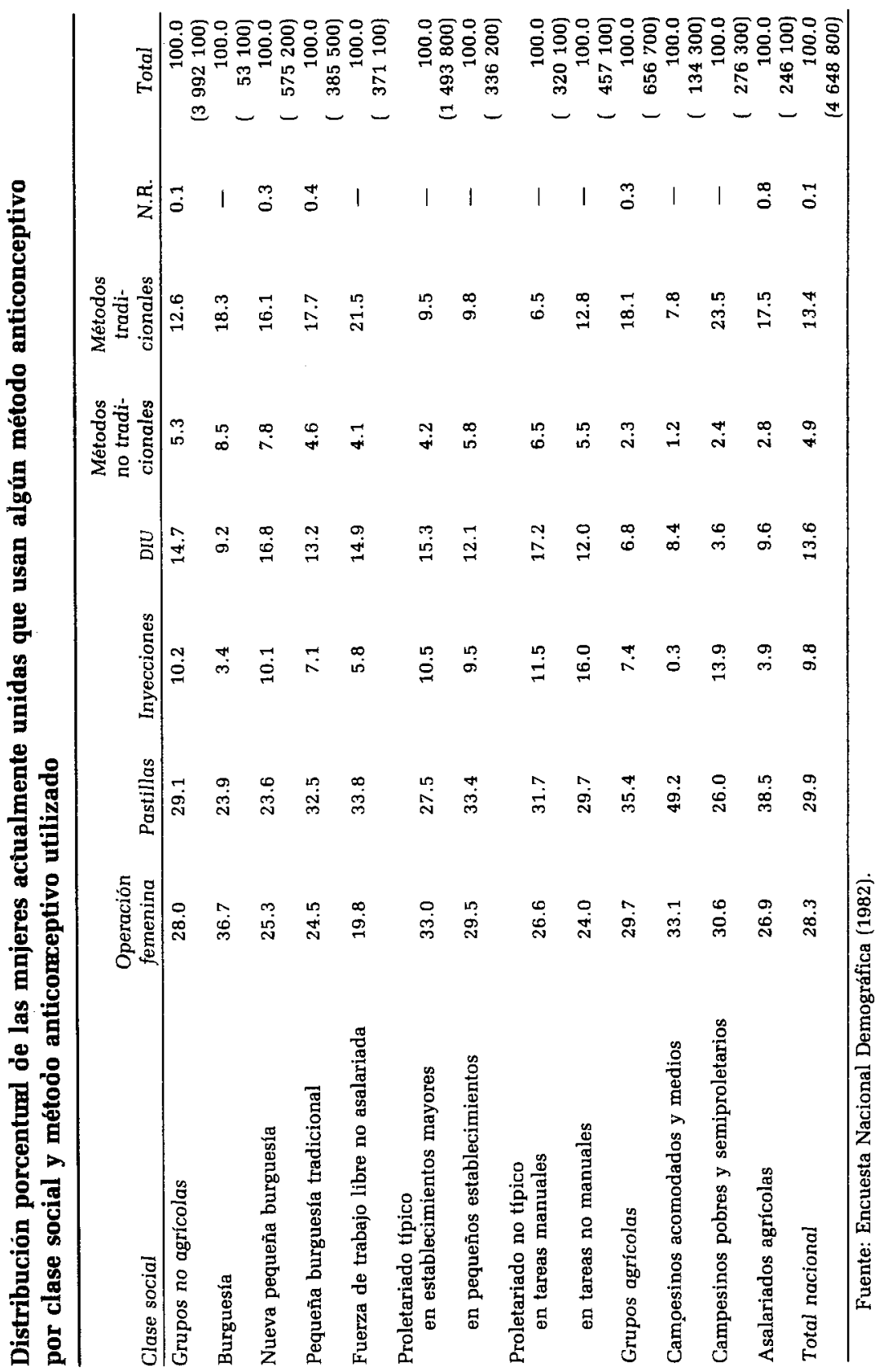




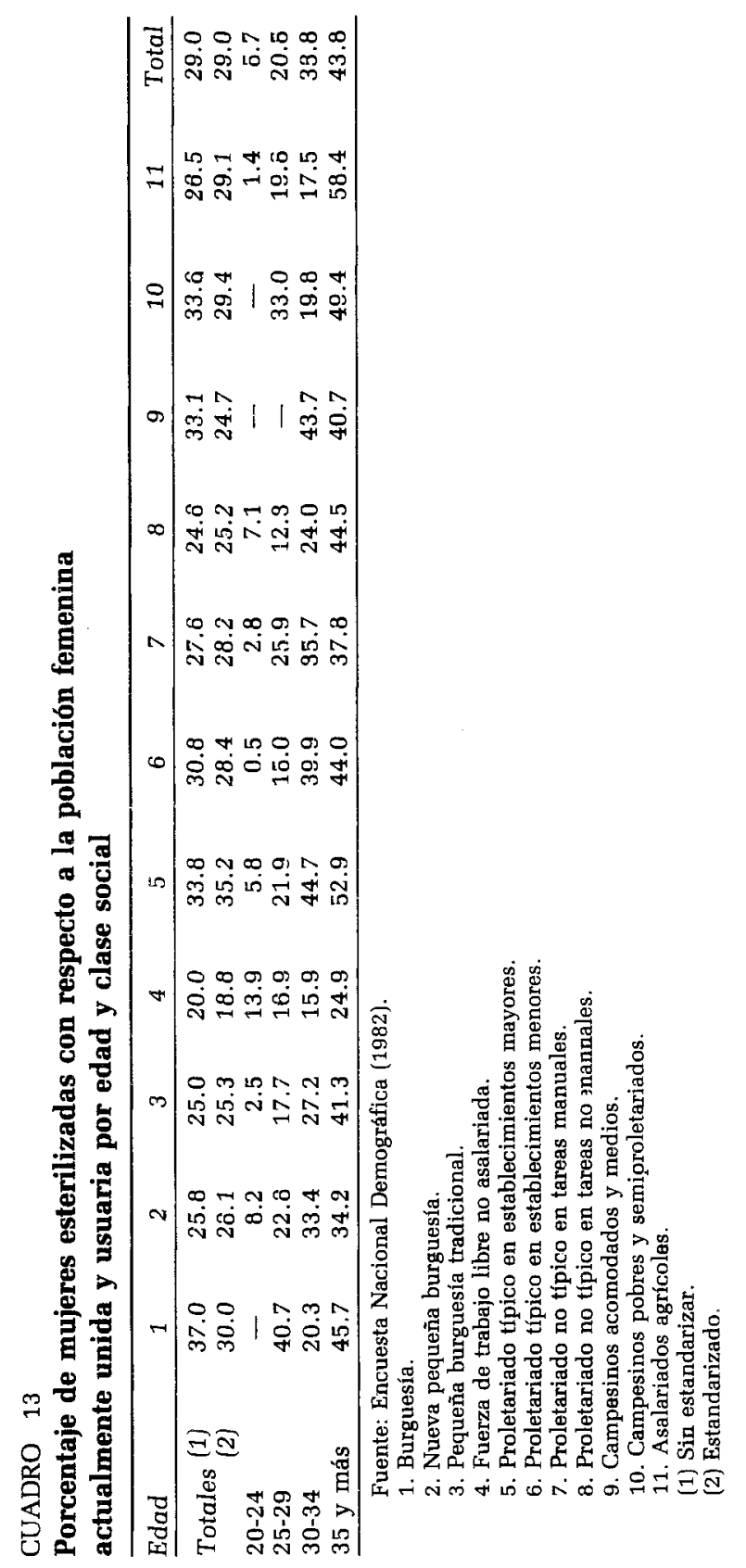



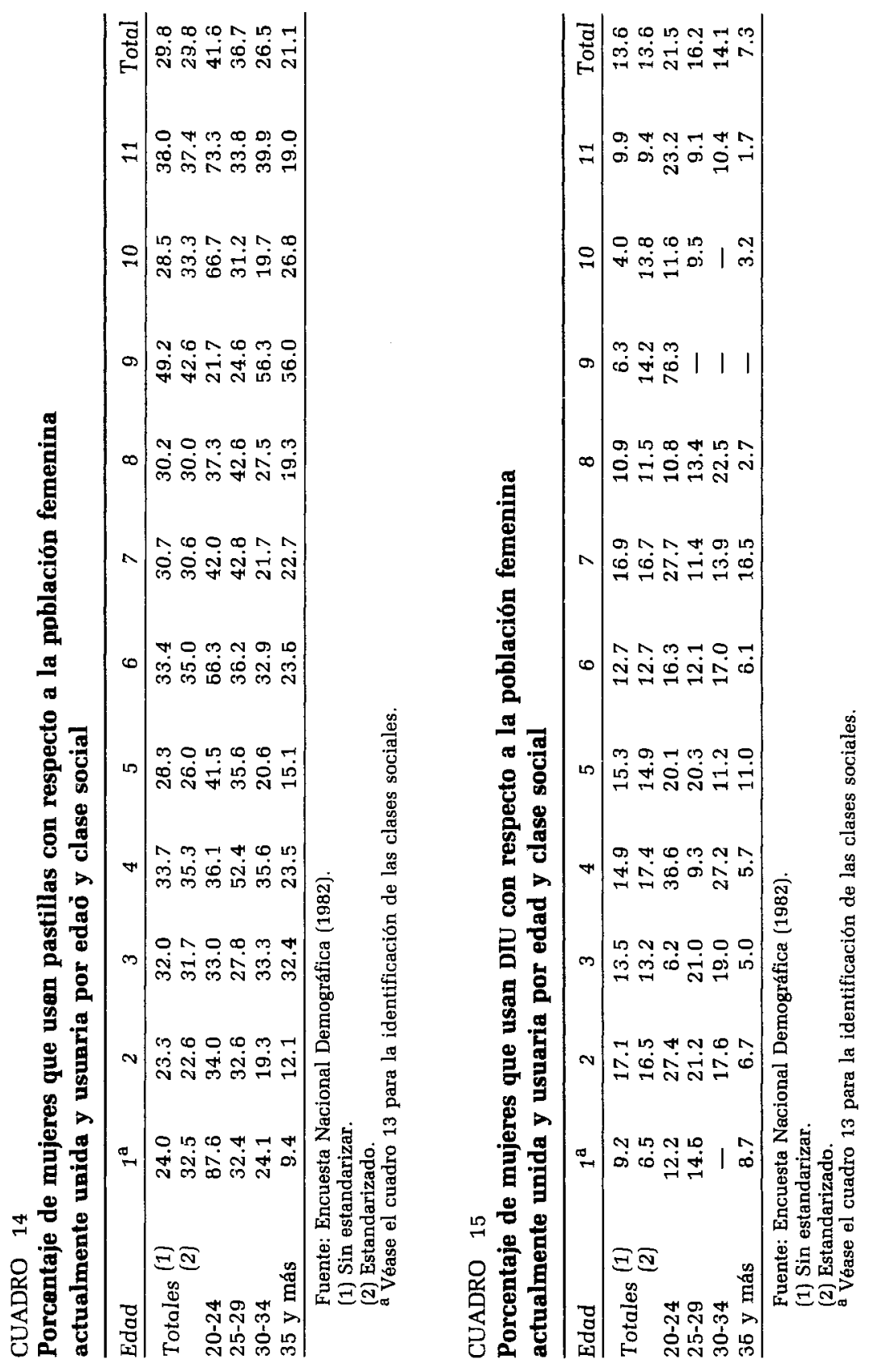


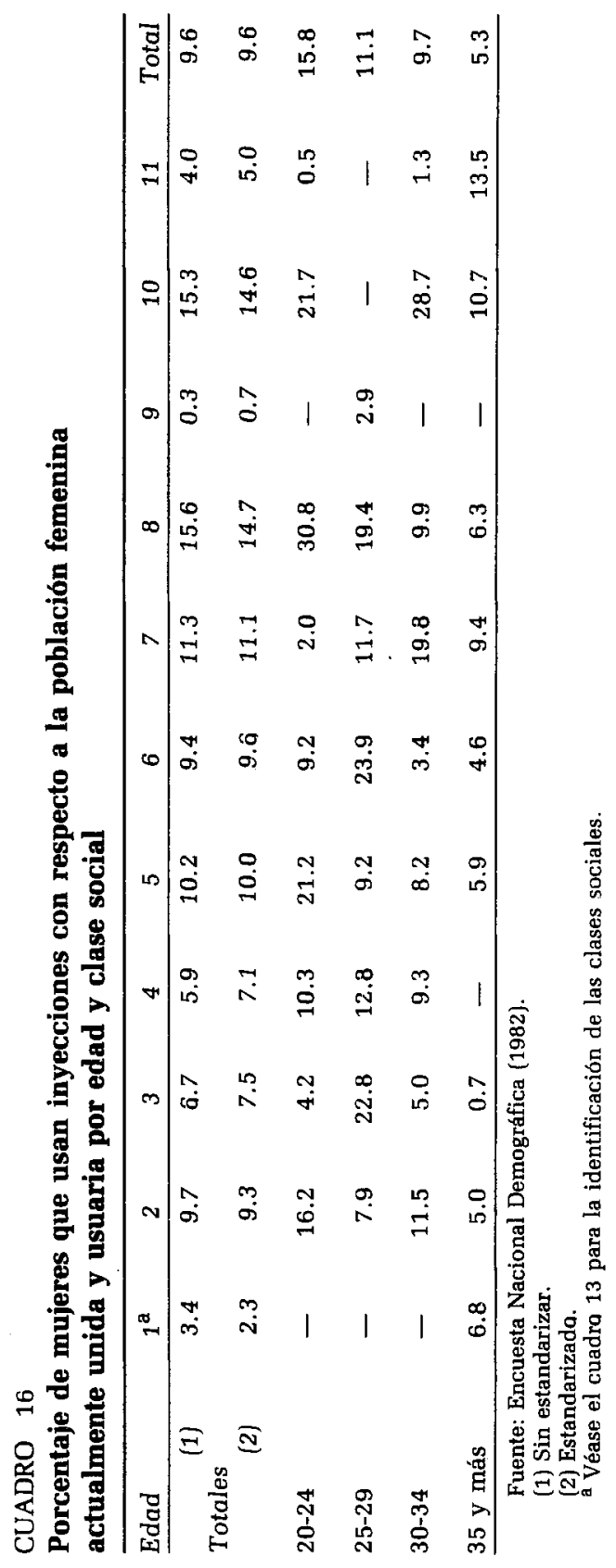


3) Las usuarias jóvenes rara vez recurren a la esterilización. Este hecho es particularmente evidente entre las mujeres de 20 a 24 años. Quizá la única excepción sean las integrantes del grupo "fuerza de trabajo "libre' no asalariada", que registra una proporción bastante alta de esterilizadas respecto al total de usuarias en este grupo etáreo (13.9\%). Sin embargo, a partir del grupo 25-29 años de edad, la proporción de mujeres que recurren a la esterilización experimenta aumentos notables entre las distintas clases sociales. De hecho, entre las mujeres ubicadas en ese grupo etáreo que pertenecen a seis distintos sectores sociales (la nueva pequeña burguesía, la fuerza de trabajo "libre" no asalariada, el proletario típico en establecimientos mayores, el proletario no típico en tareas manuales y el proletario agrícola) la esterilización es el método más utilizado después de la pildora. En estos grupos sociales las mujeres que tenían entre 25 y 29 años presentaban valorès de esterilización que oscilaban entre 17 y 26 por ciento de las unidas y usuarias de métodos anticonceptivos. Además, aunque el tamaño de la muestra exige ser cauteloso en las conclusiones, entre la burguesía y los campesinos pobres y semiproletarios el método más usado en este grupo de edad es la esterilización.

4) La proporción de usuarias que utilizan pastillas tiende a reducirse a partir de los 30 años de edad. Un análisis por clase permite mostrar que la preferencia por este método tiende a disminuir notablemente en casi todos los grupos sociales.

5) A partir de los 30 años, la esterilización es el método más utilizado en casi todas las clases sociales. Con excepción de la pequeña burguesía tradicional, de la fuerza de trabajo "libre" no asalariada y de los grupos agrícolas, en las clases restantes se registran en el grupo etáreo 30-34 una mayor preferencia por la esterilización. Cabe hacer notar que este método es, a partir de los 35 años, predominante en todos los sectores sociales, con excepción de los campesinos acomodados y medios. Llama la atención que en casi todas las clases sociales se observan proporciones de uso de este método muy elevadas en las mujeres mayores de 30 años. Baste señalar a manera de ejemplo que entre las usuarias que pertenecen al proletariado típico en establecimientos mayores, una de cada dos mujeres en esas edades ha sido esterilizada.

\section{Tipo de método, lugar de obtención y clase social}

Un área de estudio de particular interés es la que se refiere a la fuente o canal a través del cual las mujeres unidas y usuarias obtienen el método anticonceptivo que utilizan. En esta sección del trabajo se pretende examinar esta temática, tratando de evaluar el papel que han desempeñado los sectores público y privado en el aprovisionamiento de anticonceptivos dentro de cada clase social. 
La evidencia disponible revela que a nivel nacional poco más de $51 \%$ de las usuarias actuales obtienen sus anticonceptivos en alguna institución gubernamental (IMSS, ISSSTE, SSA, ${ }^{2}$ etc.), mientras que alrededor de $47 \%$ de ellas recurren al sector privado (farmacias, consultorios, etc.) para el aprovisionamiento del método de su predilección.

Entre los organismos gubernamentales que ofrecen servicios de planificación familiar destaca el IMSS, cuyo programa absorbe a poco más de $31 \%$ de las usuarias. El ISSSTE, la SSA y otras instituciones activas gubernamentales son, en conjunto, la fuente de aprovisionamiento de más de $20 \%$ del total de las usuarias unidas.

El cuadro 17 permite mostrar que el lugar donde las mujeres obtienen el método de su preferencia es diferencial por clase social. Los datos disponibles indican que los sectores que más utilizan los servicios de los organismos gubernamentales son las distintas fracciones del proletariado, la fuerza de trabajo "libre" no asalariada, y los campesinos pobres y semiproletarios. Sin embargo, cabe señalar que aun entre estos grupos existen diferencias bastante marcadas en cuanto a la institución del Estado que los provee de anticonceptivos. En términos generales, puede señalarse que el IMSS y el ISSSTE atienden preferentemente a las mujeres que integran el proletariado más estable, mientras que la SSA dirige su atención y sus recursos hacia los grupos sociales que tienen menor acceso a la seguridad social. Esta situación es particularmente evidente entre los grupos agrícolas, así como entre la fuerza de trabajo "libre" no asalariada. En estos grupos, aproximadamente entre el 25 y el 30 por ciento de las usuarias activas recurren a los hospitales, clínicas y centros de salud de la SSA, mientras que a nivel nacional esta misma institución atiende solamente a cerca de $15 \%$ de las mujeres unidas que practican actualmente la anticoncepción.

Entre los grupos que muestran proporciones elevadas de usuarias unidas que recurren preferentemente a clínicas, consultorios y hospitales privados se cuentan la burguesía, la nueva pequeña burguesía, y los campesinos acomodados y medios. De hecho, entre las integrantes del primer grupo, cerca de $50 \%$ de las usuarias obtienen por esta vía el método anticonceptivo que utilizan; es decir, una cantidad que alcanza a ser más de tres veces mayor que el observado a nivel nacional. En los otros dos grupos las proporciones varían entre el 30 y el 32 por ciento.

Cabe hacer notar que en casi todas las clases sociales un importante porcentaje de usuarias obtiene el método de su preferencia en los establecimientos farmacéuticos. Entre los grupos no agrícolas las proporciones de usuarias que recurren a esta vía varían desde $26.6 \%$, en el caso del pro-

2 IMSS: Instituto Mexicano del Seguro Social. ISSSTE: Instituto de Seguridad y Servicios Sociales de los Trabajadores del Estado. SSA: Secretaría de Salubridad y Asistencia, actualmente Secretaría de Salud. N. de la R. 


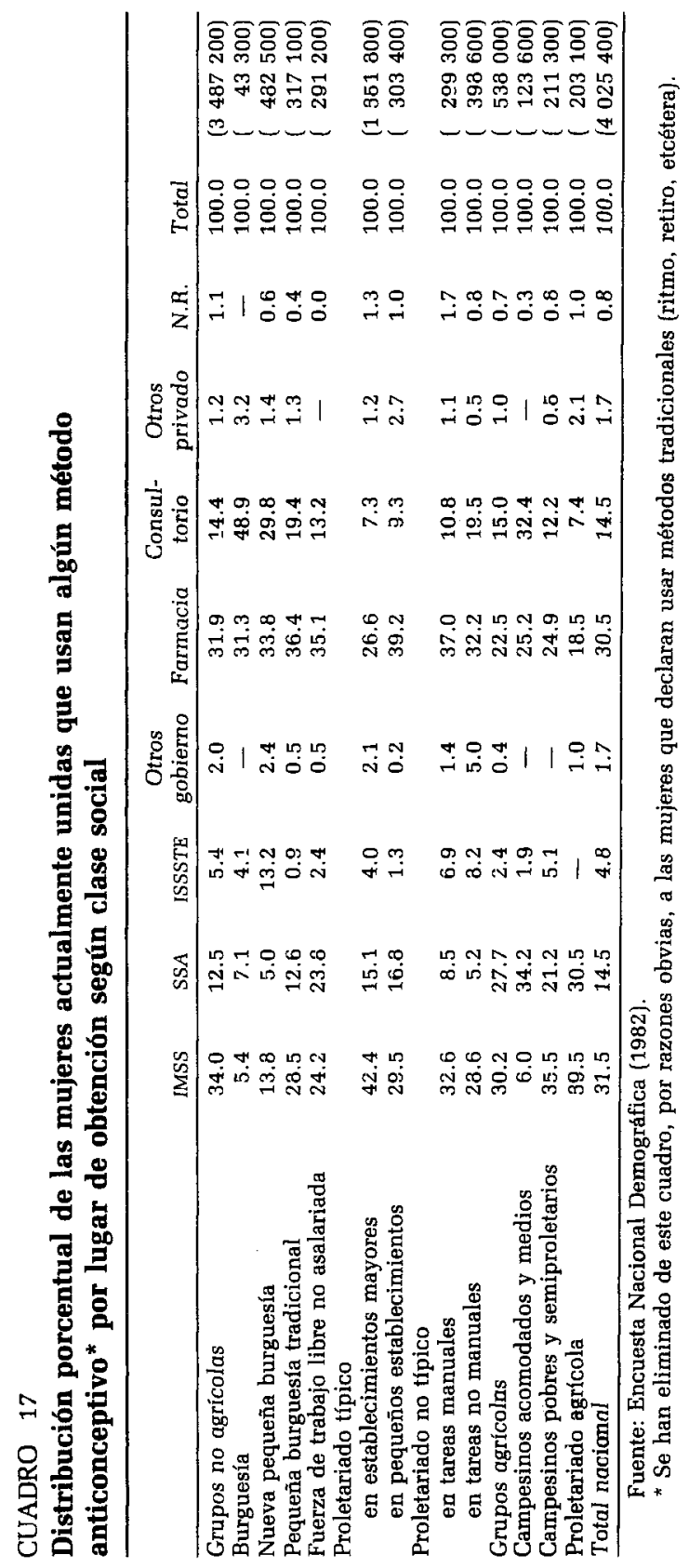


letariado típico en establecimientos mayores, hasta $37.0 \%$ en el del proletariado no típico en tareas manuales. A su vez, entre los grupos agrícolas se observan niveles menores que fluctúan entre 19 y 25 por ciento del total de usuarias.

Al relacionar el tipo de método y el lugar en que éste se obtiene de acuerdo a la clase social de pertenencia, se agregan al análisis nuevos elementos que contribuyen a precisar el papel que han desempeñado los sectores público y privado en el suministro de anticonceptivos a los distintos sectores de la población. El cuadro 18 incluye solamente los dos métodos más utilizados por las usuarias unidas, es decir, las pastillas y la esterilización. De los datos contenidos en ese cuadro pueden desprenderse las siguientes conclusiones:

1) Como ya se ha señalado, el método más utilizado en casi todos los grupos sociales es la pildora anticonceptiva. La evidencia disponible revela que este método generalmente es obtenido en los establecimientos farmacéuticos. De hecho, a nivel nacional se observa que $59 \%$ de las usuarias obtienen las pildoras por este medio. Resulta de gran interés examinar ahora si este patrón se reproduce entre las distintas clases sociales.

a) Los datos del cuadro 18 permiten mostrar que la gran mayoría de las entrevistadas que integran los grupos no agrícolas recurren preferentemente a establecimientos farmacéuticos. Sin embargo, es conveniente hacer notar que existen variaciones de acuerdo a la clase social de pertenencia. En la burguesía, la nueva pequeña burguesía y el proletariado típico en establecimientos menores, se observa que entre 70 y 75 de cada 100 mujeres que usan este método se dirigen invariablemente a las farmacias; en el resto de las clases no agrícolas se registran niveles menores, alcanzando valores cercanos a $60 \%$. La única excepción a la pauta descrita la constituye el proletariado no típico en tareas no manuales (35\%).

Este hecho se relaciona con la mayor frecuencia con que los grupos proletarios recurren a los programas de planificación familiar del sector gubernamental. Como antes señalamos, puede afirmarse que el IMSS y el ISSSTE proveen de pildoras anticonceptivas a una cantidad importante de sus derechohabientes, los que, generalmente, forman parte del proletariado más estable, mientras que la SSA tiende a cubrir al sector más vulnerable de la población no asalariada, como es el caso de la fuerza de trabajo "libre".

b) En los grupos agrícolas, el porcentaje de usuarias unidas que se aprovisionan de pastillas en las farmacias es menor que el observado entre los grupos no agrícolas. Alrededor de la mitad de las mujeres que integran el sector campesino recurre a dichos establecimientos, mientras que en el proletariado agrícola sólo lo hace una tercera parte del total. Este comportamiento puede vincularse con la creciente participación de la SSA como proveedora de los grupos que no tienen acceso a la seguridad social.

2) Con respecto a la operación femenina, el cuadro citado permite mos- 


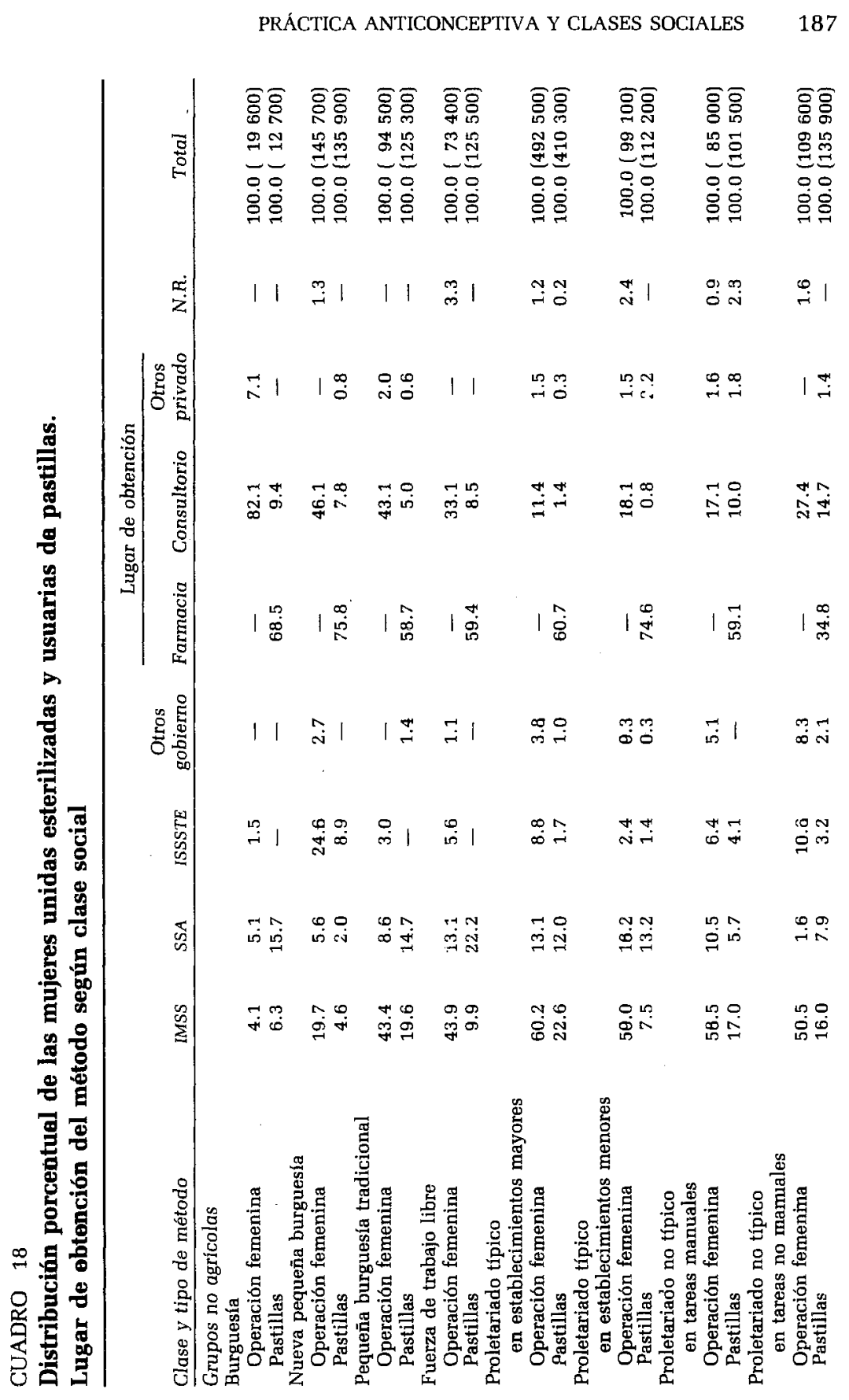


188 ESTUDIOS DEMOGRÁFICOS Y URBANOS

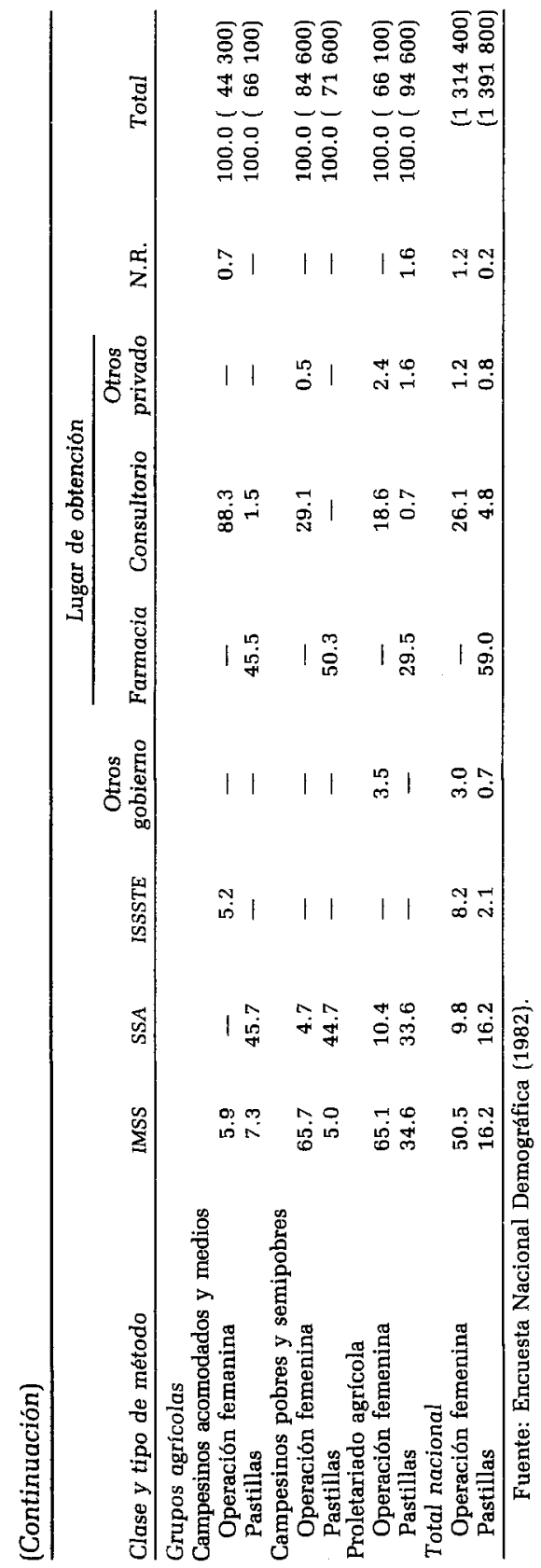


trar que el IMSS ha realizado la mayor parte de las esterilizaciones que se registran en los grupos asalariados. De hecho, entre el 50 y el 65 por ciento de las mujeres esterilizadas que integran las distintas fracciones del proletariado han sido operadas en dicha institución. Si a esta proporción se suman las intervenciones de otros organismos gubernamentales, es posible afirmar que los hospitales, clínicas y centros de salud del sector público han realizado entre el 71 y el 86 por ciento de las esterilizaciones que se observan en los distintos grupos proletarios. En contraste, las mujeres esterilizadas que pertenecen a los grupos sociales más favorecidos han sido intervenidas principalmente en clínicas y consultorios privados. Entre las integrantes de la burguesía y de los campesinos acomodados y medios es particularmente elevado el porcentaje de mujeres esterilizadas cuya operación les fue practicada en consultorios particulares.

\section{Algunos aspectos relacionados con la esterilización}

En 1970 las mujeres esterilizadas constituían $8.9 \%$ de las usuarias de métodos anticonceptivos. Este porcentaje se incrementó en los años siguientes, llegando a ser de $23.5 \%$ en 1979 y de $28.1 \%$ en 1982 . Este aumento de $216 \%$ es el cambio más notable que registran las pautas anticonceptivas de la población femenina mexicana. En otras palabras, ningún descenso y ningún aumento de los demás métodos muestran una magnitud como la señalada. De esta manera, la esterilización femenina ha pasado a convertirse en el segundo método utilizado, en términos de su prevalencia y, a no dudarlo, pasará a ser el primero en las próximas mediciones si se mantienen las tendencias actuales. El carácter irreversible de este método, que imprime un efecto permanente sobre la regulación de la fecundidad, hace relevante describir y analizar las características asociadas a su difusión.

El lector observará que el número total de mujeres esterilizadas varía en algunos cuadros. Ello se debe a la diversidad de los universos considerados.

El total de 1323200 corresponde a las mujeres esterilizadas entre 15 y 49 años durante el periodo 1970 y 1981 (cuadros 19 y 21). Los totales utilizados en los cuadros 20 , y 22 a 26 hacen referencia al mismo universo, excluyendo a las mujeres que no fueron categorizadas en ninguna clase social por falta de información. Algunas diferencias numéricas menores en los totales se deben a pérdidas de casos por falta de respuesta en ciertas variables utilizadas.

El total de 1314400 utilizado en el cuadro 18 agrupa a todas las mujeres unidas entre 15 y 49 años que fueron esterilizadas. Finalmente, el total de 1362300 corresponde al total de mujeres esterilizadas actualmente, sin considerar el estado conyugal ni el momento de la esterilización. 
ESTUDIOS DEMOGRÁFICOS Y URBANOS
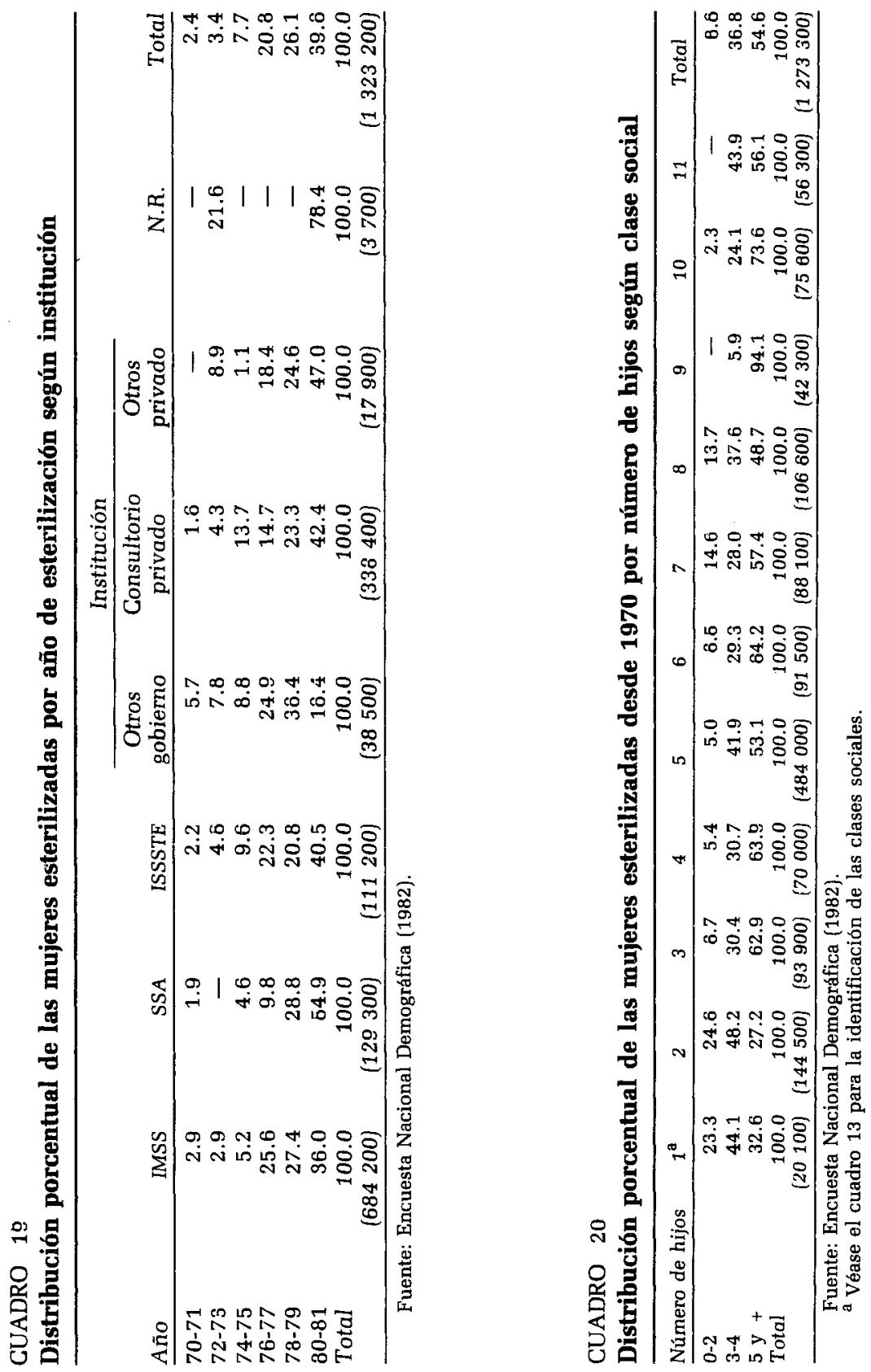
PRÁCTICA ANTICONCEP'TIVA Y CLASES SOCIALES 191

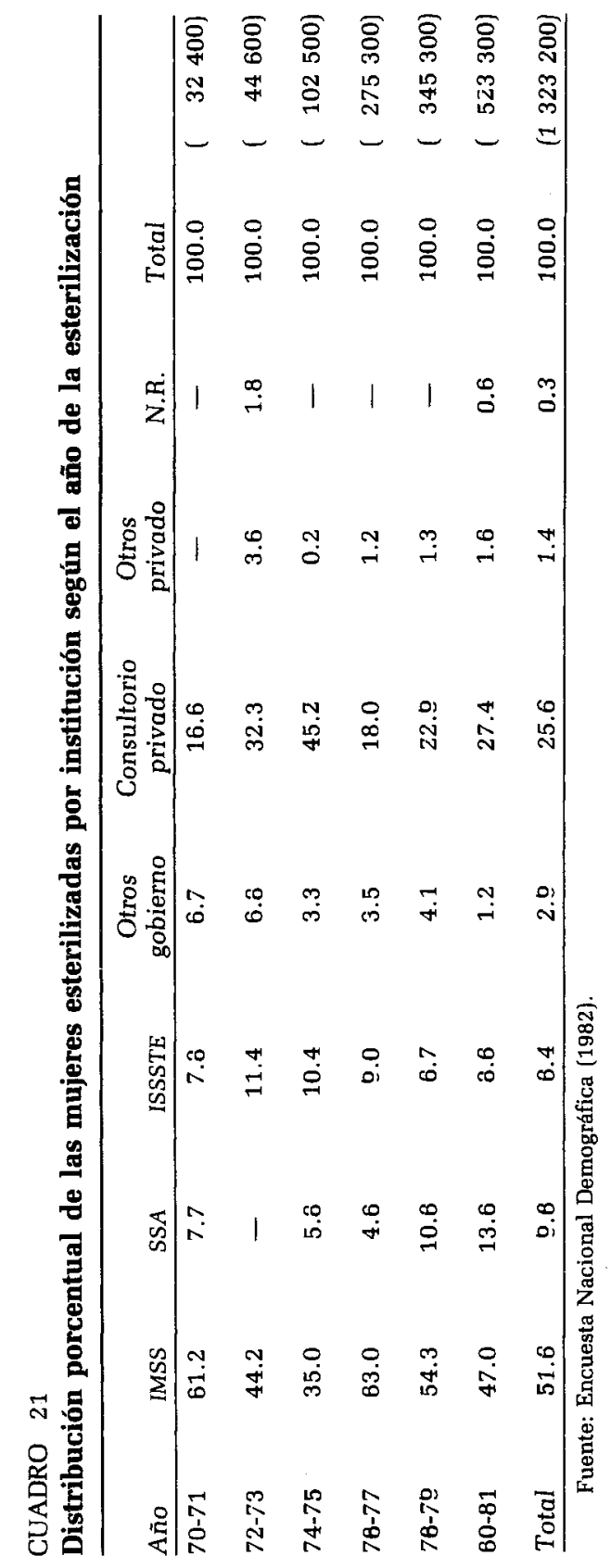


Durante los doce años anteriores a la END (1970-1981), se hicieron alrededor de 1300000 esterilizaciones femeninas. Esta cifra subestima el total de esterilizaciones realizadas en el periodo, ya que la encuesta, por razones obvias, sólo toma en cuenta a las mujeres entre 15 y 49 años sobrevivientes y residentes en el país. Casi la totalidad de las esterilizaciones fueron efectuadas en los años que van de 1976 a 1981 (86.5\%); asimismo, puede notarse que el volumen de las intervenciones quirúrgicas de los años 1980-1981 duplicó al de las de 1976-1977. La importancia de este aumento se evidencia con la comprobación de que por cada operación efectuada en el bienio 1970-1971, se hicieron 16 en el de 1980-1981 (cuadro 19).

Como era de esperar, del total de esterilizaciones la mayoría se concentra en mujeres con cinco hijos y más (54.5\%), siguiendo en orden de importancia las que tienen entre tres y cuatro hijos ( $36.8 \%$ ) y, por último, las que tienen dos o menos. En el cuadro 20 se puede ver la relación entre el número de hijos y la pertenencia de clase de la población esterilizada. En la mayoría de los grupos sociales la pauta descrita también se conserva, aunque con variaciones. Los dos grupos sociales que escapan a la distribución prototípica son la burguesía y la nueva pequeña burguesía. En estas clases, la mayor concentración se produce en las mujeres con tres y cuatro hijos, siendo muy equilibradas las categorías extremas.

Al estudiar la relación entre la población femenina esterilizada por fecha de operación y la institución que la practicó, puede verse (cuadro 21) que, entre 1970 y 1981, algo más de la mitad de las operaciones fueron efectuadas por el IMSS (51.6\%) y una cuarta parte de manera privada. La SSA y el ISSSTE en conjunto no alcanzaron a cubrir la quinta parte de las operaciones femeninas definitivas en ese mismo periodo. En total, el sector gobierno realizó $73 \%$ de las esterilizaciones.

Las medidas resumidas citadas no dejan ver algunos datos interesantes, como éstos:

1) Entre 1970-1971 y 1974-1975, el IMSS descendió su participación relativa casi a la mitad (de 61 a 35 por ciento), aun cuando aumentó el número absoluto de sus intervenciones quirúrgicas; simultáneamente, la consulta privada la aumentó a más del doble (de 17 a 45 por ciento). En contraste, tanto la SSA como el ISSSTE muestran valores porcentuales relativamente pequeños de participación en los métodos irreversibles, para los mismos años.

2) La participación del IMSS vuelve a aparecer de manera importante en 1976-1977, sobre todo por los volúmenes de poblaciọ́n que comienzan a engrosar el grupo de usuarias de métodos anticonceptivos definitivos. En esos años, el IMSS lleva a cabo las dos terceras partes de las operaciones femeninas, mientras que el sector privado conserva un porcentaje importante (18). En los años siguientes (1978-1981), es posible observar un cambio interesante: el descenso relativo de las operaciones hechas por el 
IMSS unido al crecimiento porcentual de las que se practicaron en la SSA y en el sector privado. Este hecho puede relacionarse con la evolución que han seguido las diferentes clases sociales en el total de esterilizaciones efectuadas. Retomaremos luego esta relación, pero antes intentaremos caracterizar el perfil de las operaciones femeninas por edad y clase social.

Todas las clases sociales exhiben un patrón homogéneo en cuanto al periodo en que se concentra la esterilización femenina. Como se dijo, esto fue durante 1976-1981: en la mayoría de los grupos sociales, más de $80 \%$ de la población femenina esterilizada fue operada durante esos años. Las mujeres de la burguesía son una excepción a esta modalidad: optaron por este método mucho más tempranamente que el resto de las clases; alrededor de la cuarta parte del total de sus operaciones se produjeron en el periodo 1970-1975. Otros grupos, como la nueva pequeña burguesía, la fuerza de trabajo "libre" no asalariada y el proletariado no típico en tareas no manuales realizaron una quinta parte de sus operaciones antes de 1976. La pauta global, sin embargo, está determinada por otros grupos sociales, al concentrar la abrumadora mayoría de las esterilizaciones en los últimos seis años del periodo. Tal es el caso de las dos fracciones del proletariado típico ( 88.2 y 89.8 por ciento), la fracción del proletariado no típico en tareas manuales ( $89.4 \%$ ), y la pequeña burguesía tradicional $(87.0 \%)$, así como el proletariado agrícola (97.2\%) y los campesinos pobres y semiproletarios (93.4\%) (cuadro 22).

Estos datos parecen apoyar la hipótesis que postula la existencia de modalidades diferenciales por clase en la prevalencia de la esterilización. En términos generales, se puede afirmar que entre los grupos no agrícolas, la esterilización, en estos últimos años, se ha intensificado selectivamente en los sectores más estables del proletariado, mientras que en los grupos agrícolas otro tanto ha sucedido con las clases más numerosas y menos favorecidas de la estructura social.

Analizando la relación entre la clase social y el año de la esterilización desde otra perspectiva (cuadro 23), se puede ver que en todos los bienios el proletariado típico en establecimientos mayores fue el grupo social que concentró la mayor proporción de esterilizaciones. Sin embargo, las oscilaciones han sido importantes, ya que entre 1970 y 1971 esta clase agrupó a $48.5 \%$ del total de las intervenciones, mientras que entre 1974 y 1975 el porcentaje bajó a $29.0 \%$. Queda como dato destacable que el peso de este grupo en el total de esterilizaciones en todos los bienios es siempre mayor que el que tiene en el total de la población. Además, cualquier análisis debe privilegiar lo acontecido en este grupo, por la dramática evidencia de sus valores absolutos: alrededor de 500000 mujeres de esta fracción del proletariado son irreversiblemente estériles, y una quinta parte de ellas tienen menos de 30 años.

La burguesía es otra clase social en la que la esterilización es el método predominante, incluso con proporciones mayores que las del grupo 

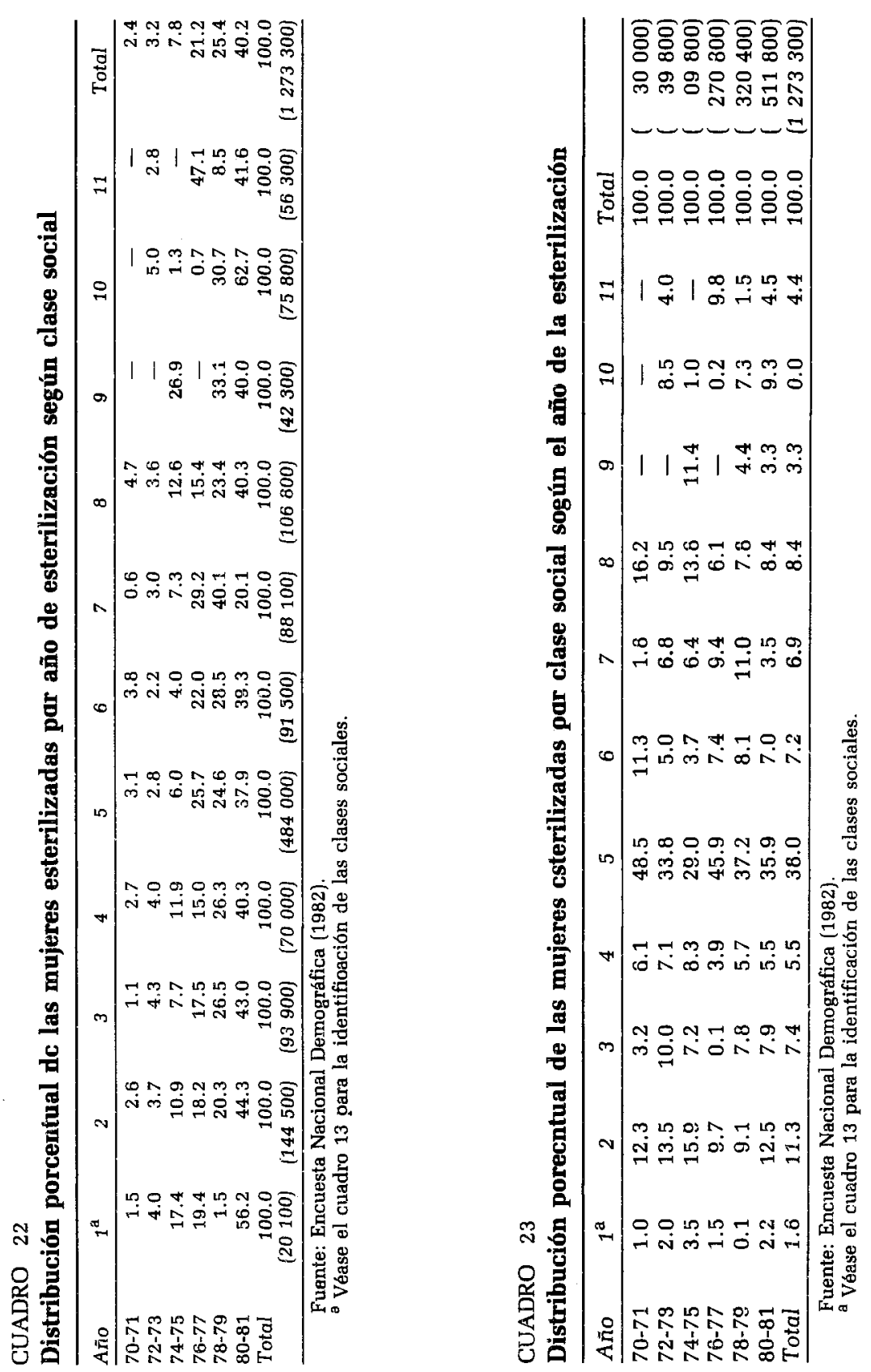
recientemente analizado ( $39.8 \%$ ). Sin embargo, su peso en términos de valores absolutos es sensiblemente menor, habiendo 24 esterilizaciones en el proletariado típico por cada una de la burguesía.

Si bien en el capítulo anterior se presentaron las relaciones entre edad, clase social y método anticonceptivo, vale la pena enfatizar las principales conclusiones con respecto a la relación entre las dos primeras variables en las mujeres esterilizadas.

El cuadro 13 muestra las tasas de esterilización según edad y clase social entre usuarias, y de su lectura se pueden inferir distintos comportamientos. Algunos de los datos más relevantes son los siguientes: a) en el grupo de 25 a 29 años de edad la tasa más alta corresponde a la burguesía; b) en el grupo de 30 a 34 años las tasas más elevadas corresponden al proletariado típico en establecimientos mayores; c) en los grupos de 35 años y más, el valor mayor de la tasa se ubica en el proletariado agrícola, y d) en el grupo etéreo más joven son las mujeres pertenecientes a la fuerza de trabajo "libre" no asalariada las que muestran un valor más alto. La tasa de este grupo nos indica que una de cada seis mujeres de 20 a 24 años ha finalizado su vida reproductiva.

En cuanto a la relación entre el lugar institucional de la esterilización y la evolución de ésta en el tiempo en las distintas clases sociales, nuestros datos sólo permiten mostrar algunos paralelismos cuya ligazón causal deberá ser probada en trabajos futuros.

En este sentido, cabe hacer notar las siguientes coincidencias: a) cuando aumenta el peso de las esterilizaciones de la burguesía y la nueva pequeña burguesía, aumentan también las que efectúa el sector privado; b) los años en los que el proletariado típico y el proletariado agrícola registran los porcentajes más altos de participación en el total de esterilizaciones, son también los años en los que el JMSS hegemoniza las intervenciones; c) en los últimos años, la caída en la participación relativa del IMSS es compensada, además de por el sector privado, por la SSA. En coincidencia, en estos años aumenta la participación de la fuerza de trabajo "libre" no asalariada y del campesinado.

Un análisis más detallado de este proceso deberá indagar en las relaciones entre lo que se acaba de describir y las políticas explícitas de fecundidad, o bien inferir, a partir de estos datos, la existencia de políticas implícitas.

Con el fin de profundizar en las modalidades de la esterilización femenina, nos propusimos conocer las relaciones que existen entre el momento en que ésta se efectúa y el nacimiento del último hijo nacido vivo; más específicamente, buscamos identificar la coincidencia o no coincidencia de ambos momentos.

En el cuadro 24 se presenta, para el conjunto de las mujeres esterilizadas en el periodo 1970-1981, la fecha de nacimiento del último hijo y la fecha de la esterilización. 


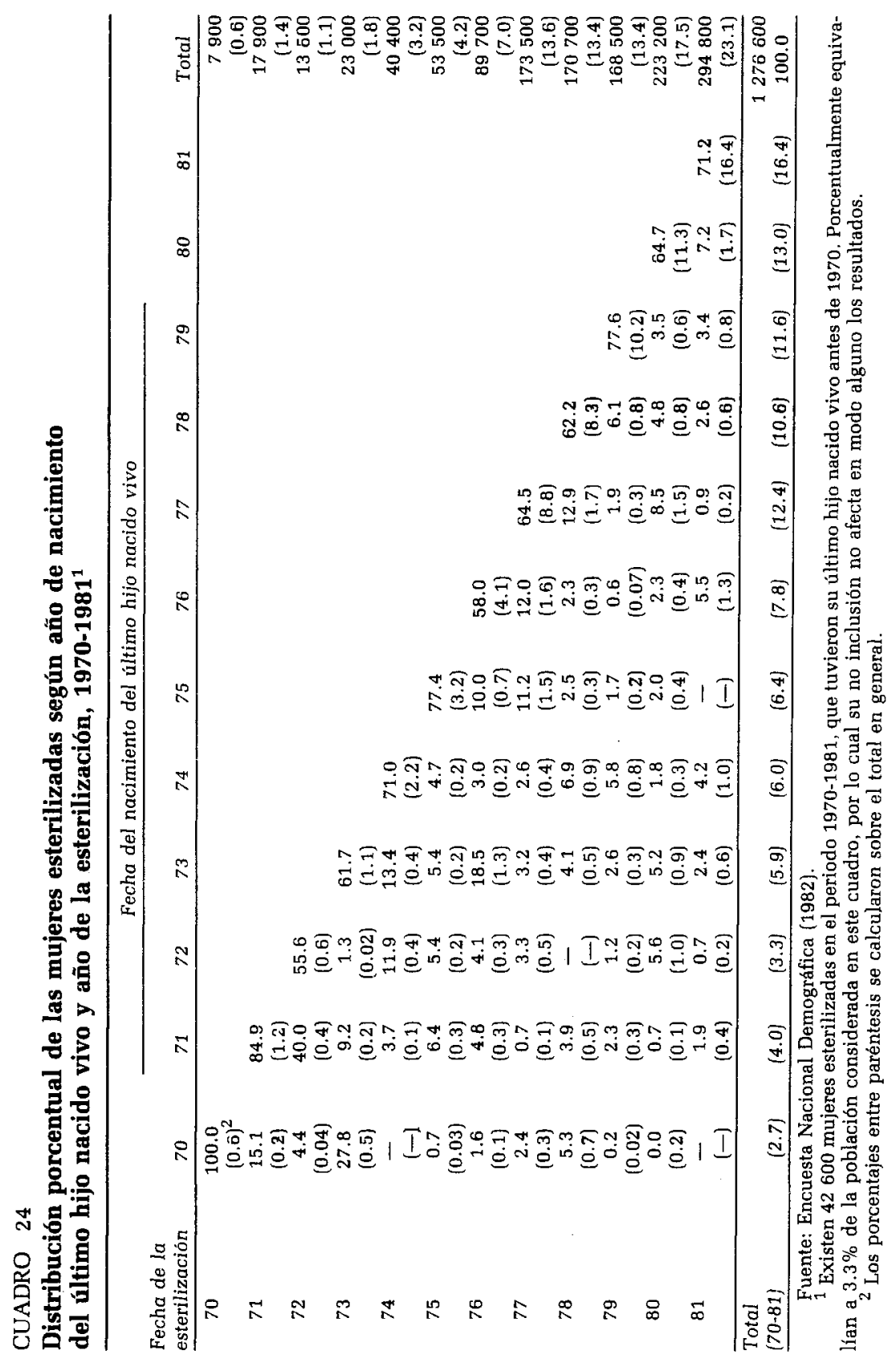


Como ya se indicó, en el periodo se hicieron alrededor del 1300000 esterilizaciones. De ellas, aproximadamente $40000(3 \%)$ corresponden a mujeres que tuvieron su último hijo antes del periodo 1970-1981. Éstas no aparecen en el cuadro, pero su número carece de peso como para afectar las distribuciones.

La principal conclusión que se extrae de la lectura del cuadro es la estrecha relación entre la fecha de la esterilización y la del último nacimiento. La concentración en la diagonal, que indica esta coincidencia, agrupa a aproximadamente 870000 mujeres, que representan a $68.0 \%$ de mujeres que se esterilizaron en esos años. Esto no se modifica cuando se lo analiza según el número de hijos tenidos, como se muestra en el cuadro 25. Del total de operaciones simultáneas, más de la mitad se hicieron a mujeres con cinco hijos y más (53.9\%) y más de la tercera parte a las de tres y cuatro hijos $(36.9 \%)$. También las operaciones femeninas postergadas, las que no se hicieron el mismo año que el parto, siguen la misma modalidad en cuanto al número de hijos.

CUADRO 25

Distribución porcentual de las mujeres esterilizadas por número de hijos nacidos vivos según condición de simultaneidad esterilización/último hijo nacido vivo

\begin{tabular}{lrrr}
\hline \begin{tabular}{l} 
Número de \\
\multicolumn{1}{c}{ hijos }
\end{tabular} & Simultáneo & No simultáneo & Totai \\
\hline $0-2$ & 9.1 & 7.3 & 8.5 \\
$3-4$ & 36.9 & 35.5 & 36.5 \\
5 y más & 53.9 & 57.2 & 55.0 \\
Total & 100.0 & 100.0 & 100.0 \\
& $(869600)$ & $(407300)$ & $(1276900)$ \\
\hline
\end{tabular}

Fuente: Encuesta Nacional Demográfica (1982).

Si se toma al conjunto de las mujeres esterilizadas, independientemente del momento y del año en que fueron operadas, y se las distribuye según el primer método anticonceptivo utilizado, se puede observar que un número importante de ellas no utilizó anteriormente ningún otro método. En otros términos, $49.3 \%$ de las mujeres esterilizadas comenzó a controlar su fecundidad con un método de carácter definitivo (cuadro 27). Este hecho debe ser, sin duda, profundizado. Para ello se deberán utilizar los datos disponibles en las encuestas ya realizadas y, sobre todo, diseñar investigaciones ad hoc que permitan dar respuesta a interrogantes cualitativas. Resulta por lo menos llamativo que mujeres que nunca hicieron nada para regular su fecundidad elijan para comenzar a hacerlo un método que, 
además de ser irreversible, conlleva toda la carga traumática asociada a cualquier intervención quirúrgica y, en especial, a una de características mutilantes.

CUADRO 26

Distribución porcentual de las mujeres esterilizadas, por condición de simultaneidad esterilización/último hijo nacido vivo, según el número de hijos nacidos vivos

\begin{tabular}{lrrrr}
\hline & \multicolumn{3}{c}{ Número de hijos } & \\
\cline { 2 - 5 } & $0-2$ & $3-4$ & 5 y más & Total \\
\hline Simultánea & 72.8 & 69.0 & 66.8 & 68.1 \\
No simultánea & 27.2 & 31.0 & 33.2 & 31.9 \\
Total & 100.0 & 100.0 & 100.0 & 100.0 \\
& $(109000)$ & $(465700)$ & $(702200)$ & $(1276900)$ \\
\hline
\end{tabular}

Fuente: Encuesta Nacional Demográfica (1982) 
PRÁCTICA ANTICONCEPTIVA Y CLASES SOCIALES 199

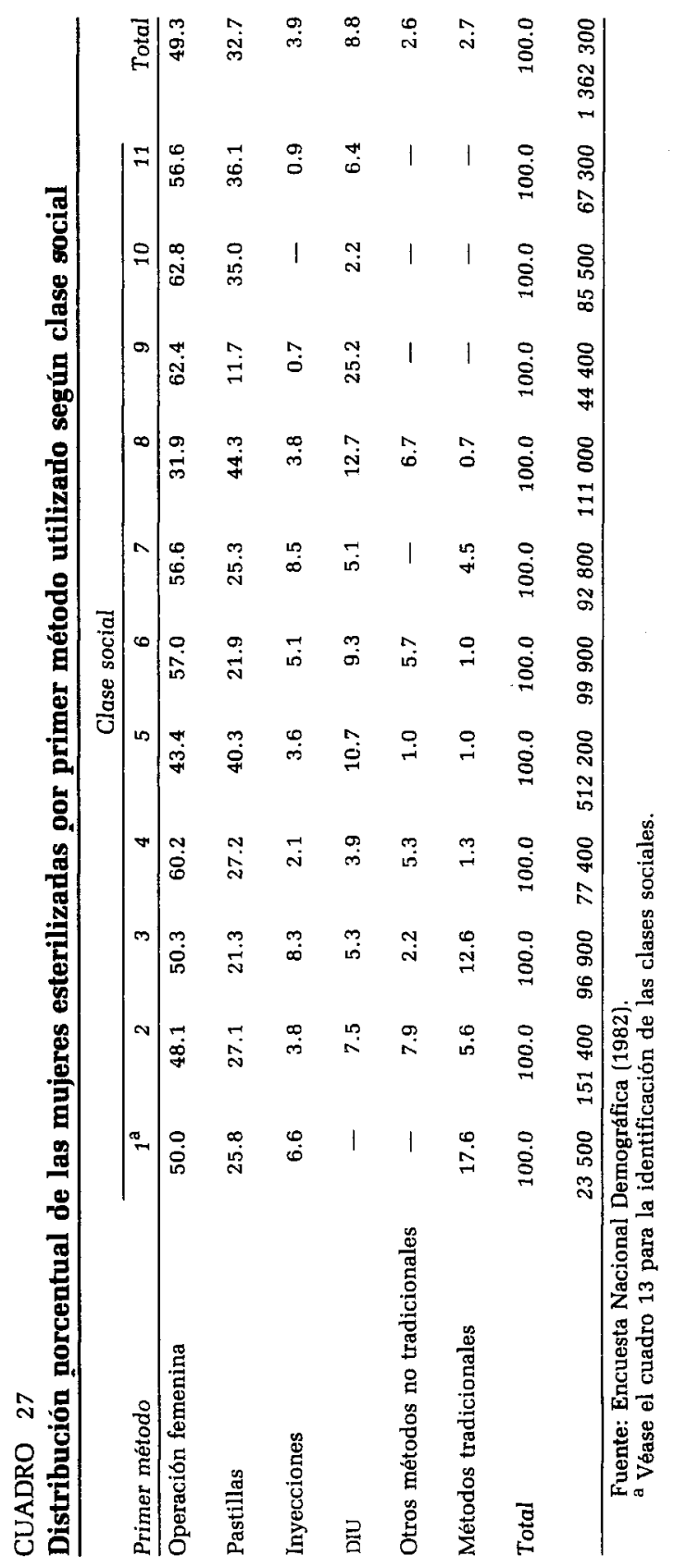




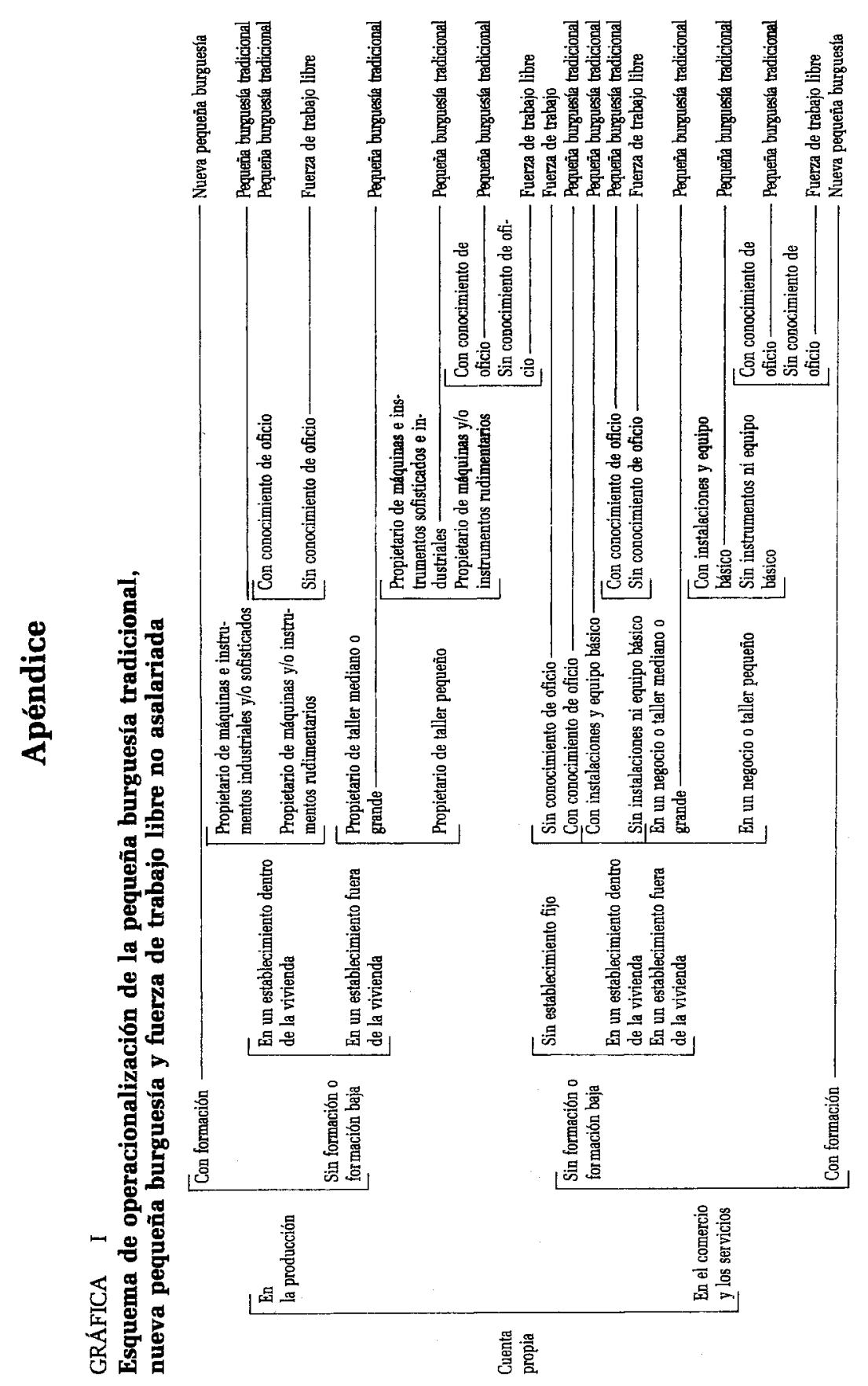




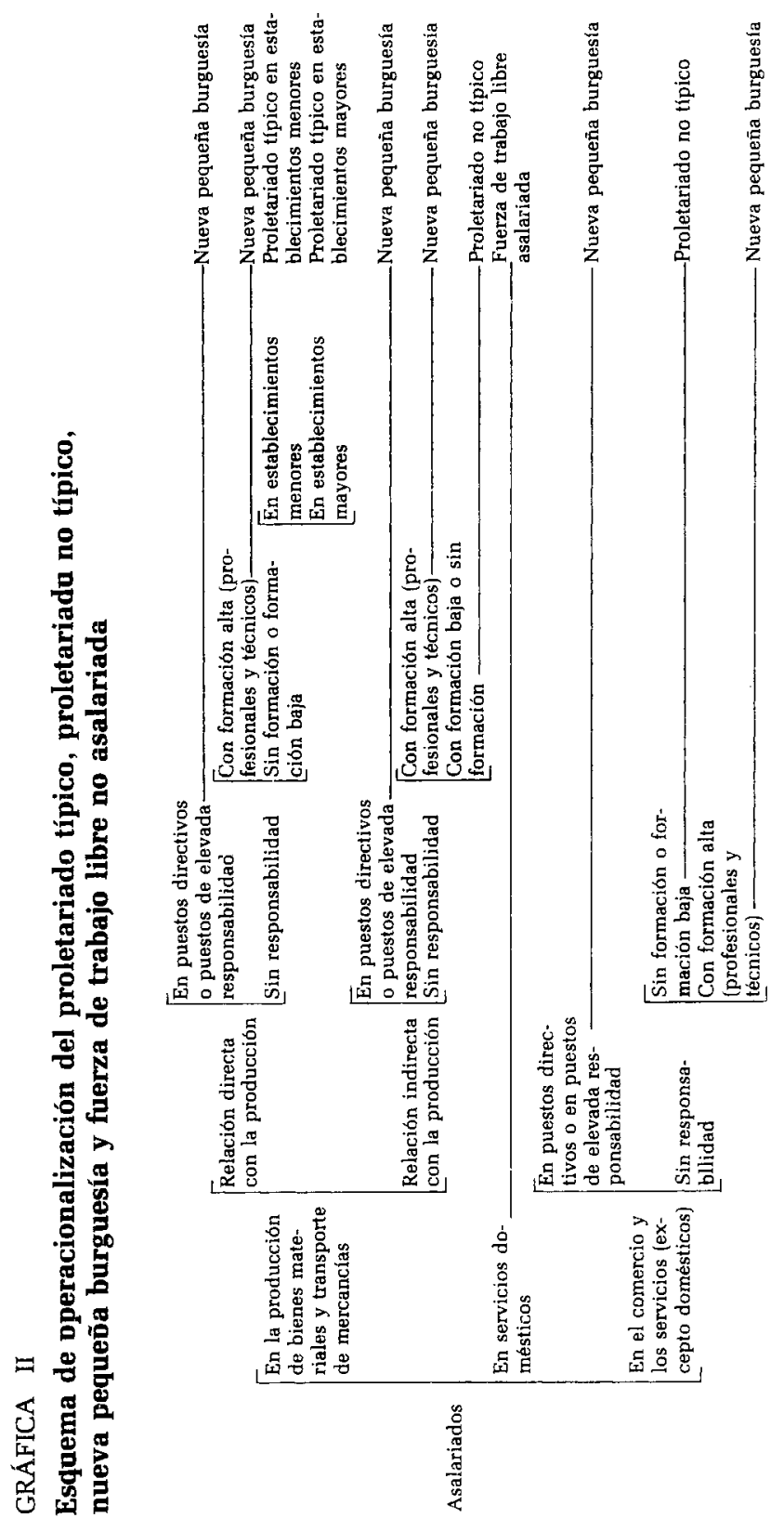




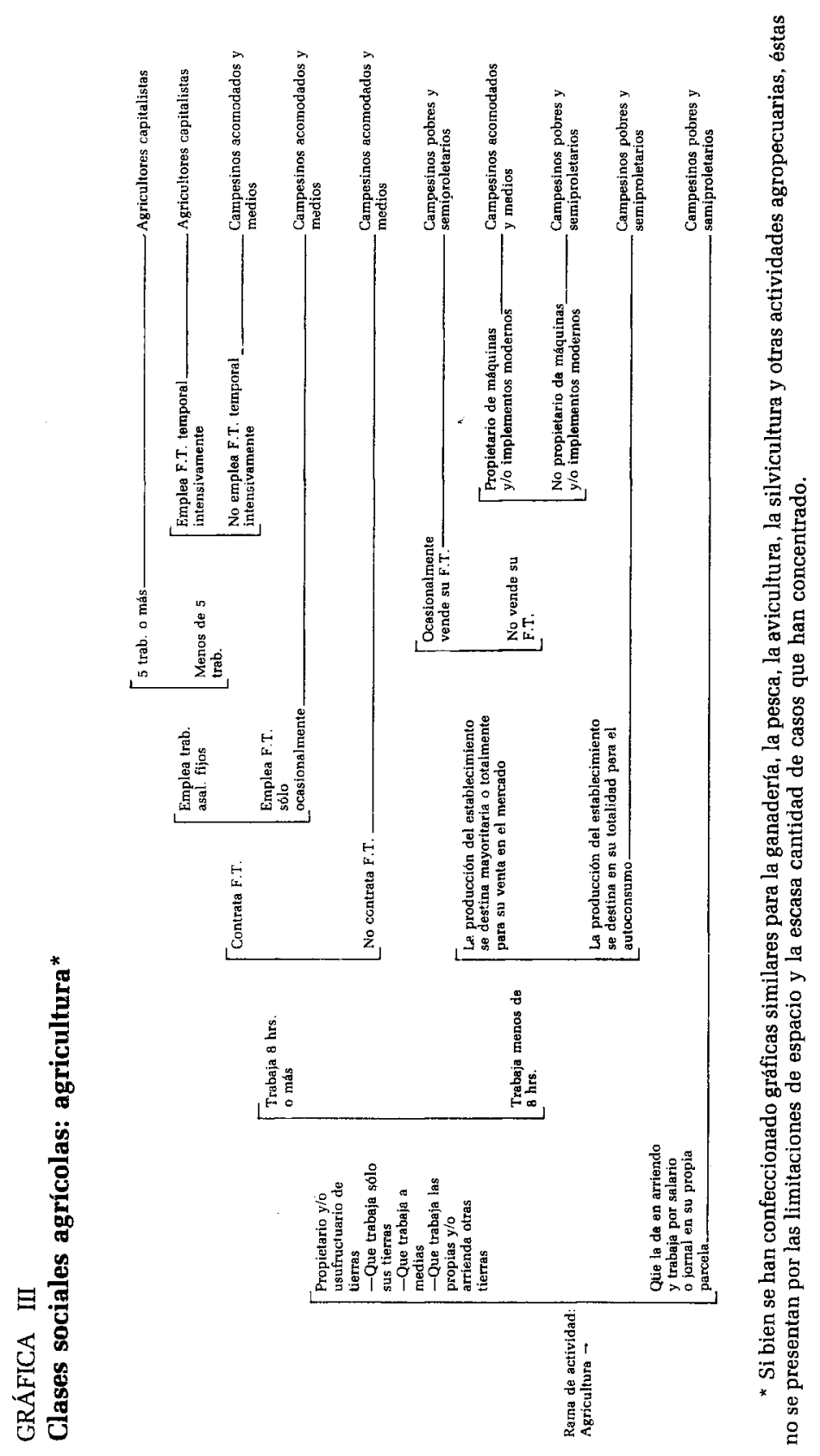




\section{Bibliografía}

Bronfman, Mario y Rodolfo Tuirán, "La desigualdad social ante la muerte: clases sociales y mortalidad en la niñez", en Memorias del Congreso Latinoamericano de Población y Desarrollo, Universidad Nacional Autónoma de México, El Colegio de México y el Programa de Investigaciones Sociales en Población, México, pp. 187-219.

Encuesta Mexicana de Fecundidad, Coordinación General del Sistema Nacional de Información, Secretaría de Programación y Presupuesto, Instituto de Investigaciones Sociales de la Universidad Nacional Autónoma de México, México, 1978.

Encuesta Nacional Demográfica, Consejo Nacional de Población, Secretaría de Programación y Presupuesto y DIF, México, 1982.

Encuesta Nacional de Prevalencia en el Uso de Métodos Anticonceptivos, Coordinación del Programa Nacional de Planificación Familiar, México, 1980. 
